\title{
Initial assessment of community midwives in rural Pakistan
}

\author{
Abdul Wajid \\ Population Council \\ Zubaida Rashid \\ Population Council \\ Ali M. Mir \\ Population Council
}

\begin{abstract}
Follow this and additional works at: https://knowledgecommons.popcouncil.org/departments_sbsr-rh
Part of the Community Health Commons, Community Health and Preventive Medicine Commons, International Public Health Commons, Maternal and Child Health Commons, Social and Behavioral Sciences Commons, and the Women's Health Commons How does access to this work benefit you? Let us know!
\end{abstract}

\section{Recommended Citation}

Wajid, Abdul, Zubaida Rashid, and Ali M. Mir. 2010. "Initial assessment of community midwives in rural Pakistan." Islamabad: The PAIMAN Project, JSI Research and Training Institute. 

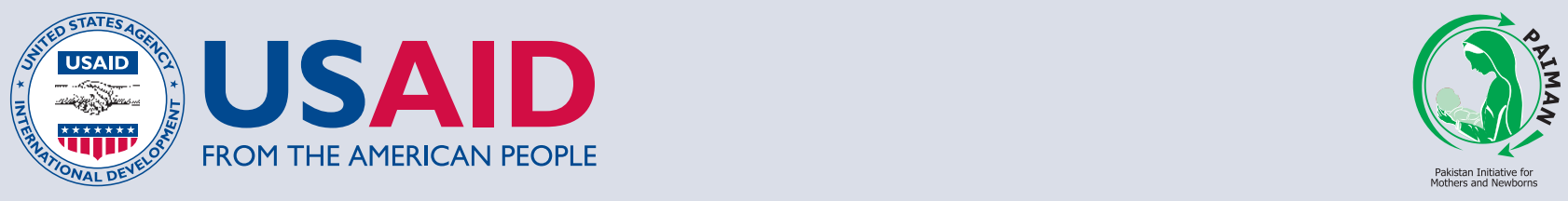

\section{Initial Assessment of Community Midwives in Rural Pakistan}



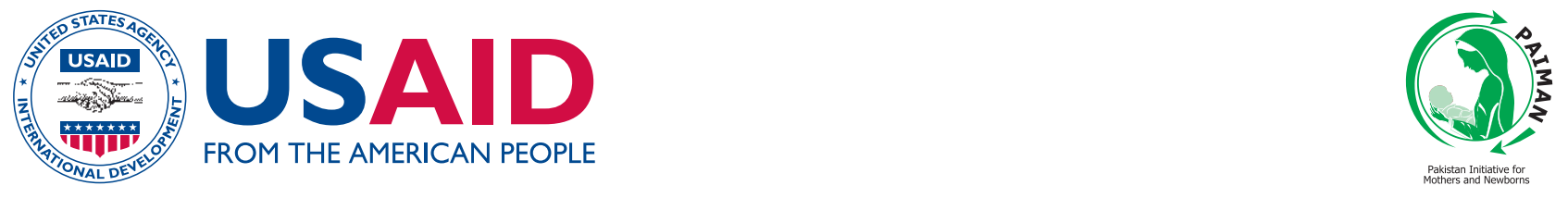

\title{
Pakistan Initiative for Mothers and Newborns (PAIMAN)
}

\section{Initial Assessment of Community Midwives in Rural Pakistan}

\author{
Abdul Wajid \\ Zubaida Rashid \\ Ali Mohammad Mir
}




\section{(1) Population Council}

The Population Council, an international, non-profit, non-governmental organization established in 1952, seeks to improve the well-being and reproductive health of current and future generations around the world and to help achieve a humane, equitable, and sustainable balance between people and resources.

The Council analyzes population issues and trends; conducts research in the reproductive sciences; develops new contraceptives; works with public and private agencies to improve the quality and outreach of family planning and reproductive health services; helps governments design and implement effective population policies; communicates the results of research in the population field to diverse audiences; and helps strengthen professional resources in developing countries through collaborative research and programs, technical exchange, awards, and fellowships.

The Population Council reserves all rights of ownership of this document. No part of this publication may be reproduced, stored or transmitted in any form by any means-electronic, photocopying, recording or otherwise-without the permission of the Population Council.

\section{For inquiries, please contact:}

Population Council

\# 7, Street 62, F-6/3, Islamabad, Pakistan

Tel: 92518445566

Fax: 92512821401

Email: pcpak@popcouncil.org

Web: http://www.popcouncil.org

http://www.paiman.org.pk

Layout and Design: Ali Ammad

Published: May, 2010

\section{Disclaimer}

"This study/report is made possible by the generous support of the American people through the United States Agency for International Development (USAID). The contents are the responsibility of JSI Research \& Training Institute, Inc and do not necessarily reflect the views of USAID or the United States Government." 


\section{Table of Contents}

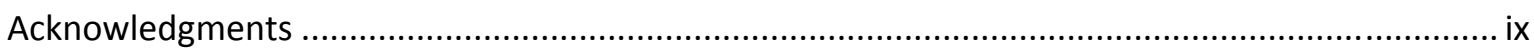

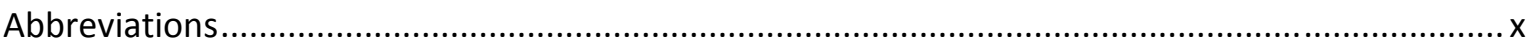

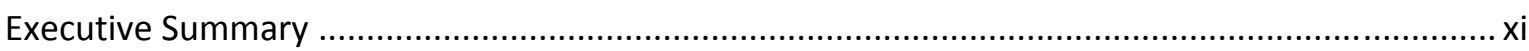

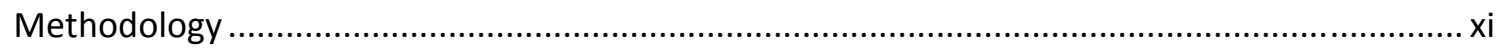

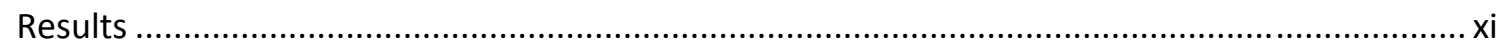

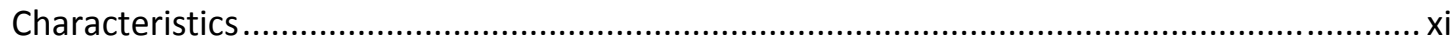

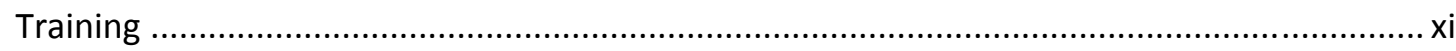

Knowledge: Maternal Health ..........................................................................................

Knowledge: Neonatal Health ....................................................................................... xii

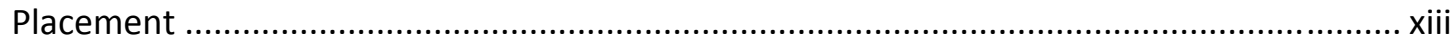

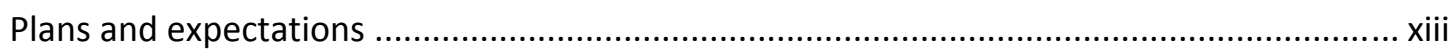

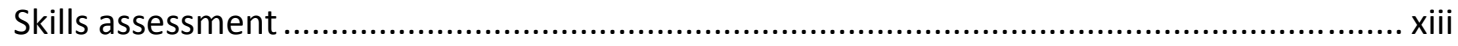

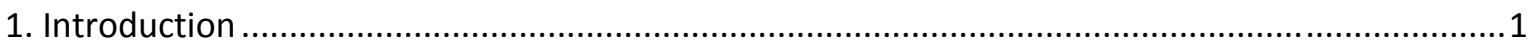

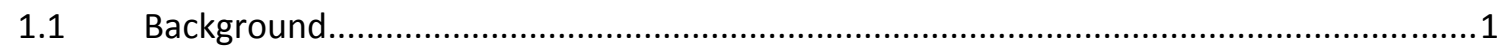

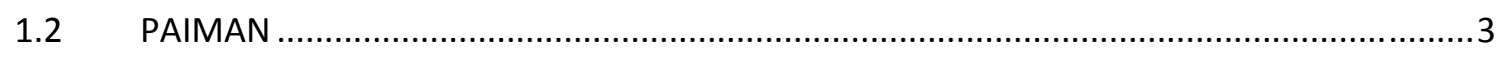

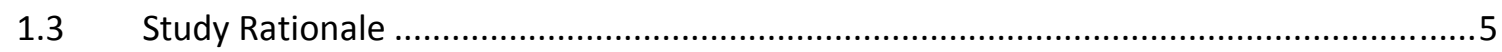

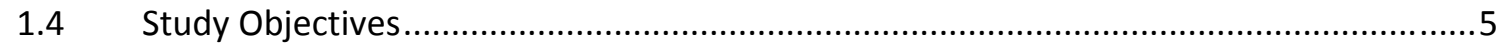

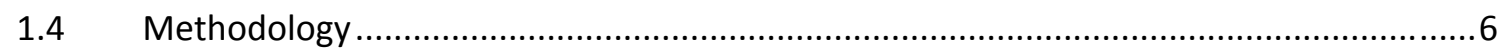

Sample

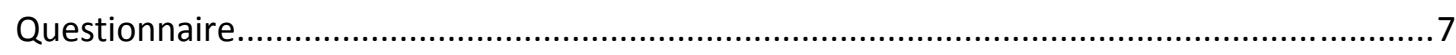

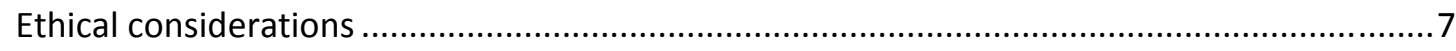

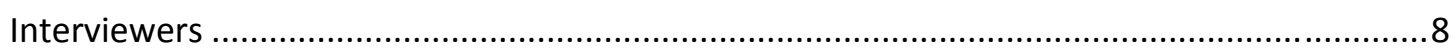

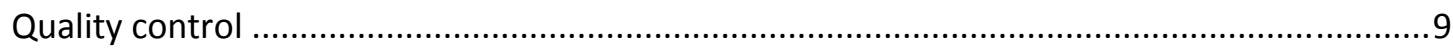

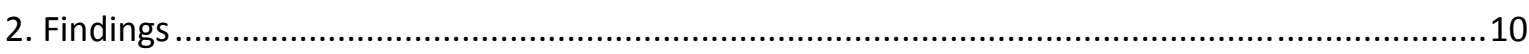

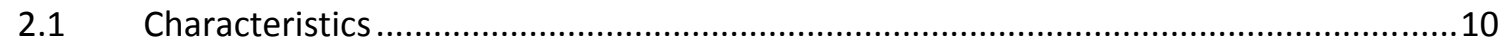

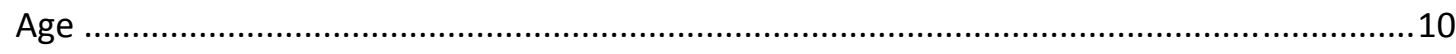

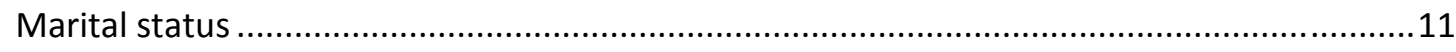

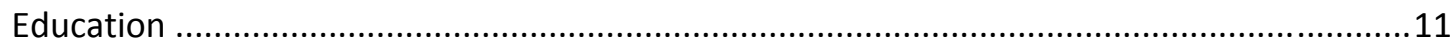

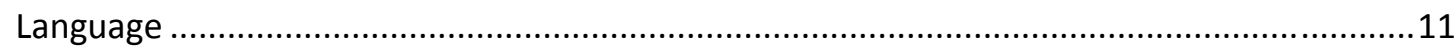

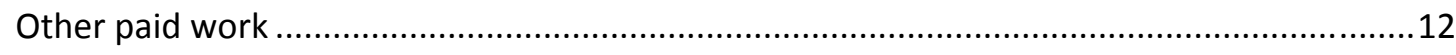

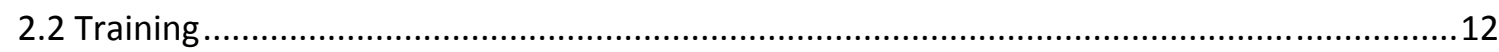

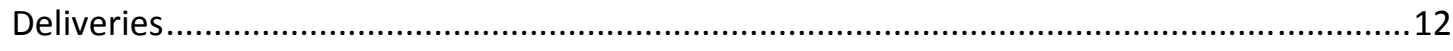

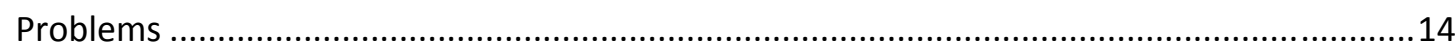

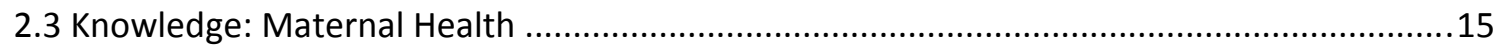

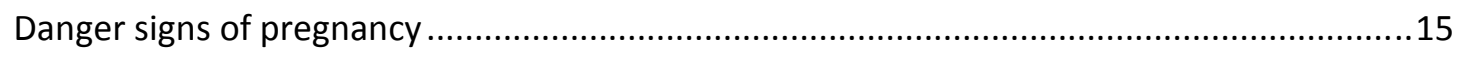

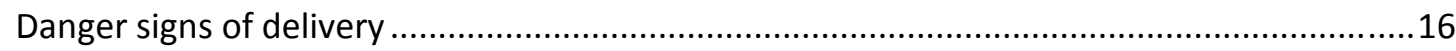

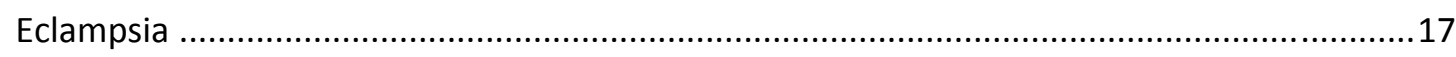

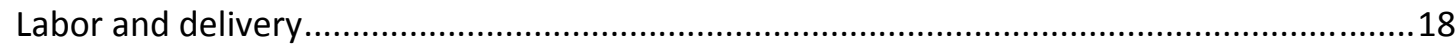




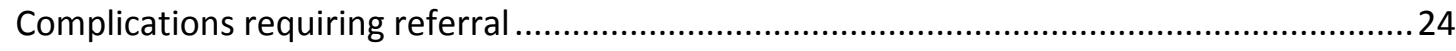

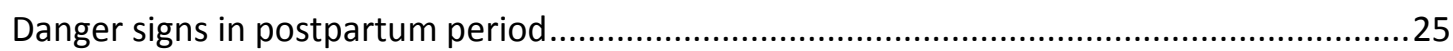

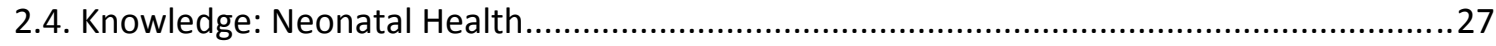

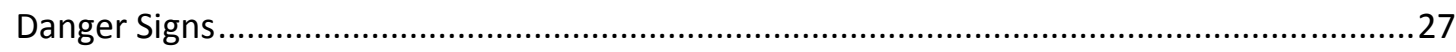

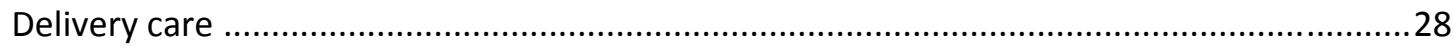

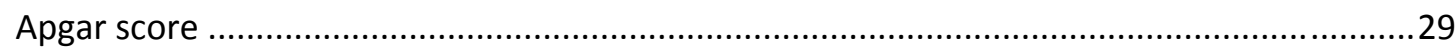

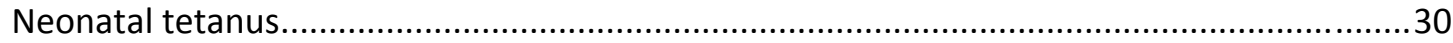

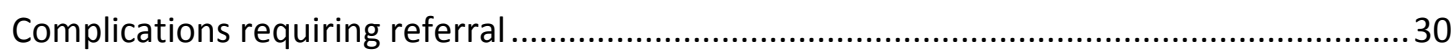

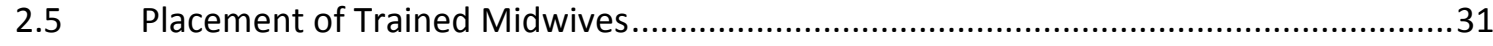

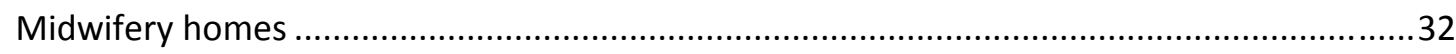

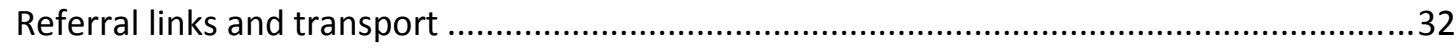

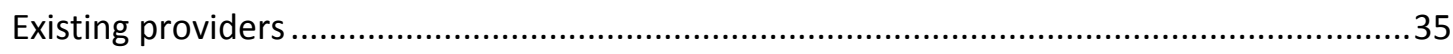

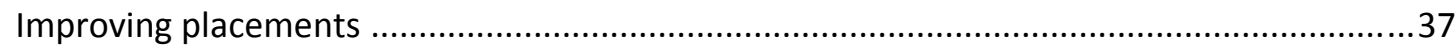

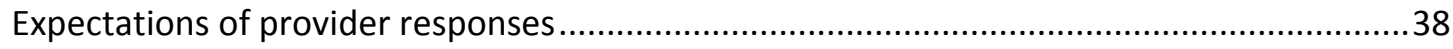

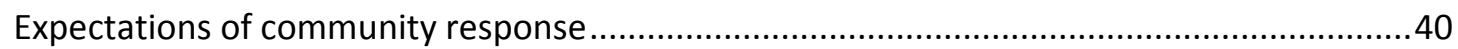

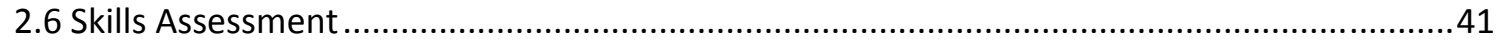

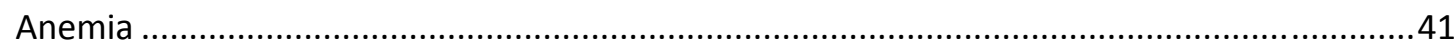

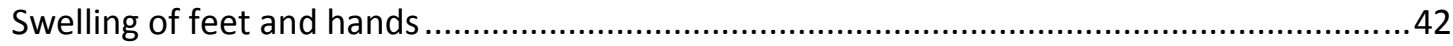

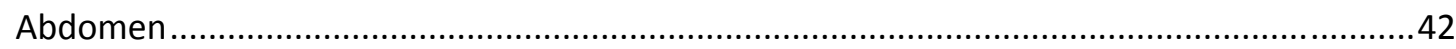

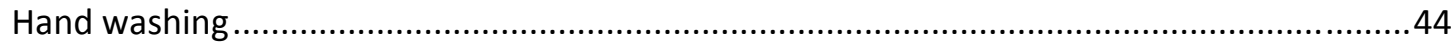

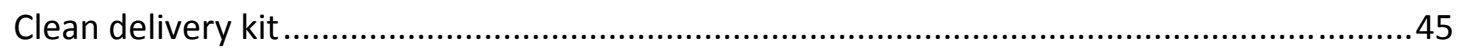

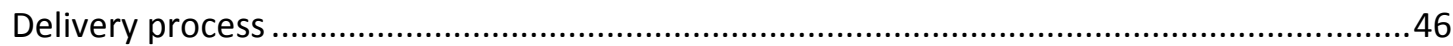

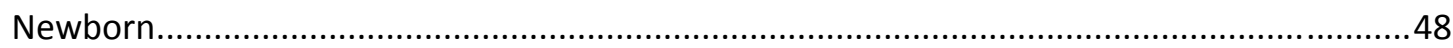

Placenta

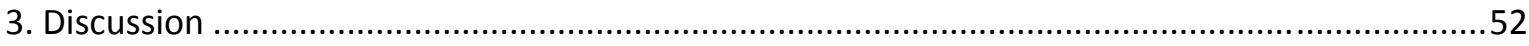

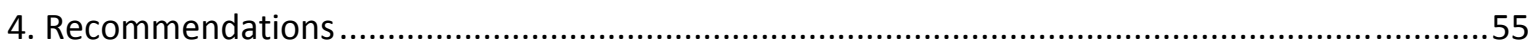

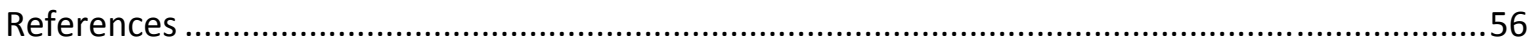

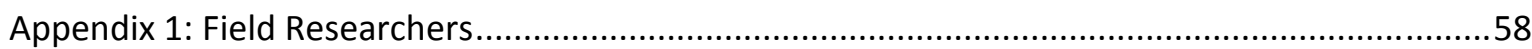




\section{List of Tables}

Table 1: Number of community midwives who spontaneously named specific danger signs of pregnancy, by district.

Table 2: Number of community midwives who spontaneously named specific danger signs of delivery correctly, by district......

Table 3: Number of community midwives who correctly knew specific components for managing eclampsia, by district.

Table 4: Number of community midwives who correctly knew specific steps in infection prevention, by district

Table 5: Number of community midwives who correctly knew specific components of a partograph, by district

Table 6: Number of community midwives, by response on frequency for vaginal examinations, according to district .

Table 7: Number of community midwives who correctly knew specific factors in identifying prolonged labor, by district.

Table 8: Number of community midwives who correctly knew specific factors in managing prolonged labor, by district.

Table 9: Number of community midwives who correctly knew specific steps in active management of third-stage of labor, by district.

Table 10: Number of community midwives who spontaneously knew postpartum danger signs correctly, by district.

Table 11: Number of community midwives who correctly knew specific steps in managing puerperal sepsis, by district.

Table 12: Number of community midwives who spontaneously knew specific danger signs in newborns correctly, by district.

Table 13: Number of community midwives who correctly knew specific steps in newborn care, by district

Table 14: Number of community midwives who correctly knew components of Apgar score, by district.

Table 15: Number of community midwives who correctly knew steps in prevention of neonatal tetanus, by district.

Table 16: Number of community midwives who had established a midwifery home, by number of rooms, by district.

Table 17: Number of community midwives who had made specific types of referral links, by district

Table 18: Number of community midwives who reported specific transport arrangements for referrals, by district

Table 19: Number of community midwives who stated specific reasons for their acceptance by community women, by district.

Table 20: Number of community midwives who gave specific suggestions for increasing acceptability in the community, by district 
Table 21: Number of community midwives who correctly assessed anemia through specific modes, by district

Table 22: Number of community midwives who correctly performed specific tasks of an abdominal checkup (on a model), by district....

Table 23: Number of community midwives who correctly performed specific steps of hand washing, by district.

Table 24: Number of community midwives who correctly performed specific skills in clean delivery kit use, by district.

Table 25: Number of community midwives who correctly performed specific steps of delivery (on a model), by district.

Table 26: Number of community midwives who correctly used specific skills in cleaning a newborn, by district. 


\section{List of Figures}

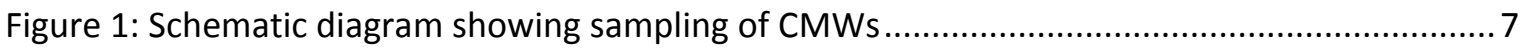

Figure 2: Percentage distribution of community midwives, by age group ..................................... 10

Figure 3: Percentage distribution of community midwives, by marital status................................11

Figure 4: Percentage distribution of community midwives, by years of education ........................ 11

Figure 5: Percentage distribution of community midwives, by language spoken in their

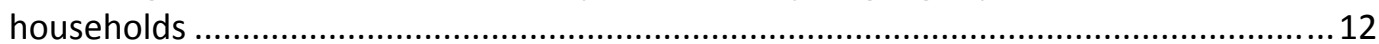

Figure 6: Percentage of community midwives who conducted 15 or more deliveries during training, by district

Figure 7: Percentage distribution of community midwives, by number of deliveries conducted, by age and marital status

Figure 8: Percentage of community midwives who reported specific problems during community training

Figure 9: Percentage of community midwives who correctly knew specific obstetrical complications requiring referral

Figure 10: Percentage of community midwives who correctly knew specific neonatal complications requiring referral

Figure 11: Percentage distribution of community midwives who knew about available transport for emergency referrals, by district.

Figure 12: Mean number of LHWs and dais in the community midwives' catchment areas, by district. 35

Figure 13: Percentage of community midwives, by nature of contact with LHWs and dais...........36

Figure 14: Percentage of community midwives stating specific roles for LHWs and dais

Figure 15: Percentage of CMWs who made specific suggestions for improving their community placements.

Figure 16: Percentage of community midwives who stated specific modes of cooperation for existing health care providers

Figure 17: Percentage of community midwives who described specific potential factors for lack of cooperation from existing health care providers

Figure 18: Percentage of community midwives who correctly carried out all steps of an abdominal examination, by district.

Figure 19: Percentage of community midwives who correctly carried out all seven steps of hand washing, by district

Figure 20: Percentage of community midwives who correctly carried out both steps in clean delivery kit use, by district

Figure 21: Percentage of community midwives who correctly carried out 4 or more steps or all 7 steps of delivery, by district.....

Figure 22: Percentage of community midwives who correctly carried out 4 or more steps or all 7 steps of cleaning a newborn, by district 50

Figure 23: Percentage of community midwives who correctly carried out all steps in examining the placenta after delivery, by district 



\section{Acknowledgments}

First and foremost, we would like to express our thanks to the Pakistan Initiative for Mothers and Newborns (PAIMAN) project for its generous funding and support for this research project. PAIMAN, in turn, was funded by the United States Agency for International Development (USAID). We are thankful to Dr. Nabeela Ali, Chief of Party for the PAIMAN project, for her encouragement and support to implement the project.

We are particularly thankful to Dr. Arshad Mahmood, head of the Operations Research Technical Working Group and Director of Research, Monitoring and Evaluation, Population Council, who supported the project in all respects.

We are most grateful to Dr. Anrudh Jain, Distinguished Scholar, Population Council, New York, for providing valuable inputs on the findings, which helped improve the interpretation and presentation. We are most thankful to Ms. Pamela Ledbetter for her meticulous review of the report and her significant editorial inputs.

The high quality of data entry and editing would not be possible without a dedicated team. We appreciate the efforts of Mr. Irfan Masood for completing the data management and analysis on time. We are indebted to Ms. Momina Salim for proofreading the report. We also thank Mr. Ali Ammad for formatting the report in a timely manner and Mr. Ahmed Hassan for providing general support in training and field activities.

Finally, we want to thank the interviewers (lady health visitors LHVs) and logistic supervisors who undertook a very challenging assignment. We must also acknowledge the contribution of all of the community midwives (CMWs) who willingly participated in the study. We hope that their time and effort will result in improvements in the CMW program in rural Pakistan. 


\section{Abbreviations}

AMTSL Active Management of Third Stage of Labor.

BCG

Bacillus Calmette-Gurin

$\mathrm{BHU}$

Basic Health Unit

CDK

Clean Delivery Kit

CMWs

Community Midwives

CSPro

Census Survey Program

$\mathrm{DHQH}$

District Headquarters Hospital

GoP

Government of Pakistan

IPC

Interpersonal Communication

IRB

Institutional Review Board

LHV

Lady Health Visitor

LHW

Lady Health Worker

$\mathrm{MCH}$

Maternal and Child Health

MMR

Maternal Mortality Ratio

MNC

Maternal, Newborn and Child Health

$\mathrm{MWH}$

Midwifery Home

OR

Operations Research

PAIMAN Pakistan Initiative for Mothers and Newborns

PNC

Pakistan Nursing Council

$\mathrm{RHC}$

Rural Health Center

SBA

Skilled Birth Attendant

SPSS

Statistical Package for the Social Sciences

TBA

Traditional Birth Attendant

$\mathrm{THQH}$

Tehsil Headquarters Hospital

USAID

United States Agency for International Development

WMO

Woman Medical Officer 


\section{Executive Summary}

Pakistan's Maternal Mortality Ratio (MMR) is 276 per 100,000 live births and Neonatal Mortality Rate (NMR) is approximately 54 per 1000 live births (NIPS, 2007). The role of a skilled birth attendant (SBA) is crucial in reducing this high level of mortality. The concept of community midwifery has been recently introduced in Pakistan. The goal of this study, funded by USAID through the Pakistan Initiative for Mothers and Newborns (PAIMAN) project, was to assess the potential of community midwifery services in rural Pakistan in order to provide necessary evidence for future decisions regarding the training, practice and placement of community midwives (CMWs).

\section{Methodology}

A total of 174 midwives, who took their final examination before the start of this project, were contacted for interviews in six PAIMAN districts: Rawalpindi, Jhelum, Khanewal, Dera Ghazi Khan (D.G. Khan), Dadu and Sukkur. After verifying their success in the final exam, residential status and establishment of midwifery homes, $106 \mathrm{CMWs}$ were selected for interviews. A structured questionnaire was used for data collection.

\section{Results}

\section{Characteristics}

The mean age of the $106 \mathrm{CMWs}$ was 25 years. Most (71) were unmarried; 35 were married. All midwives fulfilled the required educational criteria for recruitment. Across the six districts, Punjabi was the most commonly spoken language (35 percent), closely followed by Sindhi (32 percent). Only 17 midwives stated they were doing work other than their midwifery practice.

\section{Training}

An overwhelming majority of these midwives completed their training in the year 2008. Half of the midwives conducted the recommended 15 or more deliveries during their training period.

About one-quarter of the midwives (28/106) experienced problems during the community phase of the 18-month training. The most frequently encountered problems 
had to do with deficient or inappropriate introduction into the community and the young age of the respondents. Ninety-nine CMWs stated that the training increased their knowledge of maternal and neonatal health.

\section{Knowledge: Maternal Health}

The assessment of CMWs' knowledge regarding different aspects of maternal health is reflected as follows:

- Less than one-third (32) spontaneously knew three or more danger signs of pregnancy.

- Less than half (43) knew of three or more danger signs of delivery.

- Less than a fifth (20) knew any of the three steps of eclampsia management.

- Almost half (50) knew any five steps of infection prevention during delivery.

- Almost three-fourths (78) knew any three components of the partograph.

- Almost all used disposable gloves for every vaginal examination.

- About one-third (36) knew all steps of AMTSL.

- Just over two-fifths (44) knew any 3 or more postpartum danger signs.

- Just under one-third (32) knew any three steps of puerperal sepsis management.

- None of the respondents had knowledge of all danger signs and steps for managing prolonged labor.

\section{Knowledge: Neonatal Health}

The assessment of CMWs' knowledge regarding different aspects of neonatal health is reflected as follows:

- Just over half (56) knew three or more danger signs in a newborn.

- About one-tenth (12) knew any five steps of newborn care management.

- Almost half (52) knew all components of an Apgar score.

- Just over one-fifth (31) knew all steps to prevent neonatal tetanus.

- About one-seventh (15) knew all four neonatal complications requiring referral. 


\section{Placement}

At the time of interview, more than half (59) of the CMWs had started their work in the community. Most of the working midwives (48) established their midwifery house (MWH) with one room. All homes were supplied with electricity while 39 homes had water supply. A remarkably high number of midwives (100) responded that they had established linkages with some type of referral health facility. Two-thirds reported the availability of transport. The three main activities suggested by CMWs for improving their introduction to and working in their communities were: door-to-door visits, free antennal checkups and friendly attitude. Sixty-six CMWs had established working relationship with lady health workers (LHWs) and 43 with dais. Among these, some had not started their work yet but were active and developed relationships with LHWs.

\section{Plans and expectations}

Eighty-one CMWs stated that they will soon start their work by undertaking regular household visits. Eighty CMWs expected cooperation from LHWs, but fewer (50) expected cooperation from TBAs. They stated establishing "good relationship" as one way of getting cooperation from LHWs (83 CMWs) and "good skills" for getting cooperation from dais (77 CMWs). As reasons for lack of cooperation, "poor relationship" was stated mostly with regards to LHWs and professional jealously with regards to dais. The main reasons for acceptance by community women were good skills and good relationships. The majority of CMWs (87) stated that they will work towards increasing their acceptability in the community through good interpersonal communication skills (IPCs).

\section{Skills assessment}

Ninety midwives could assess anemia correctly by at least one of these three methods. Assessment of swelling on feet and hands was correctly carried out by 81 CMWs. The numbers of CMWs who correctly completed the abdominal examination for size of uterus and fetal position were 53 and 70 respectively, while 66 assessed fetal heart rate appropriately. For hand washing technique, about a quarter of the CMWs could perform four or more steps correctly.

Midwives were assessed on how adequately they conducted a delivery through the different steps. Spreading a clean or aseptic plastic sheet was performed correctly by 69 
CMWs. Cleaning the perineal area was correctly performed by $24 \mathrm{CMWs.} \mathrm{Perineal} \mathrm{support}$ was adequately done by 50 midwives. The task of holding the newborn just after delivery was not correctly performed by $63 \mathrm{CMWs}$. Wrapping the newborn in a clean cloth was correctly performed by 55 CMWs. Correct cord tying and cutting was performed by 67 and $70 \mathrm{CMW}$ s respectively.

The introduction of a new cadre of skilled birth attendants is exceptionally significant, especially at a time when Pakistan is working towards achieving the Millennium Development Goals by 2015. For a program with goals and objectives of this nature, it is important that every effort is invested in training and preparing these community midwives in conducting deliveries at the community level. Robust supervision-during training and while providing services in the communities-is imperative in ensuring that the community midwives perform at the highest levels of care. 


\section{Introduction}

\subsection{Background}

There are more than half a million maternal deaths and four million neonatal deaths a year around the world. Among these, more than 98 percent of the maternal deaths and 99 percent of the neonatal deaths occur in developing countries. Pakistan's maternal mortality ratio (MMR) is relatively high, though by no means the highest in the region, at 276 per 100,000 live births; the neonatal mortality rate is about 54 per 1000 live births (NIPS 2007).

Findings of the Pakistan Demographic and Health Survey (2007) show that only 39 percent of the deliveries in Pakistan were attended by skilled birth attendants: 34 percent of these deliveries took place at a health facility, while only 5 percent of pregnant women could utilize the services of skilled birth attendants (SBAs) in their homes (NIPS 2007). This underscores the fact that a majority of births occur at home attended by untrained traditional birth attendants (dais).

Improvement in maternal and neonatal health is largely dependent upon the availability of skilled birth attendants at the time of delivery. Sweden tackled the issue of perinatal and maternal mortality by training and deploying community midwives in the eighteenth century (Anderson et al. 2000). These midwives were backed by a team of highly skilled obstetricians in tertiary care hospitals. This model of community midwives was adopted by many other countries, which gradually improved the maternal mortality situation in these countries far before the emergence of antibiotics (Hogberg 2004). In fact, the same model is still as effective as it was in the eighteenth century.

Many countries in Asia have also taken up the model of training and establishing community midwives with promising results (Hatt et al. 2007). In Indonesia, the SBA-toclient ratio decreased, reaching the level of 1:54, due to the training and recruitment of community midwives. This improvement was also found in lower socio-economic groups (Hatt et al. 2007). Malaysia made improvements in its MMR by utilizing two main models (WHO 2005). Starting in 1970, the country utilized the services of community midwives who attended deliveries in homes and contributed toward the reduction of MMR to a level of 50 deaths per 100,000 live births. This number was as high as 320 deaths per 100,000 live births in 1957 (Koblinsky et al. 1999). 
Malaysia took the initiative of replacing traditional birth attendants by trained community midwives. In the mid 1980s, Malaysia moved towards institutionalized deliveries, which resulted in a further decrease in the MMR to 43 deaths per 100,000 live births (Koblinsky et al. 1999). This was achieved twofold: firstly, by increasing the coverage of midwives in the community and secondly, linking them to referral health facilities with accessible transport at all times. So, whenever these midwives recognized the need to refer a case for an obstetrical emergency, transportation had already been arranged.

For a country like Pakistan, where 62 percent of the population resides in rural areas with poor health-care infrastructure, skilled birth attendants are crucial to improving maternal and neonatal health. The concept of community midwifery is not new in Pakistan. The country's first Maternal and Child Health (MCH) Program was initiated in 1955, introducing a cadre of lady health visitors (LHVs). As outlined in their responsibilities, the LHVs are required to provide static as well as domiciliary services regarding maternal and child health services. They are stationed at a maternal and child health (MCH) center: a basic health unit (BHU), a rural health center (RHC), a tehsil headquarters hospital (THQ) or a district headquarters hospital (DHQ) (Department of Health 1997). The current number of registered LHVs is 6,741 (Federal Bureau of Statistics 2005). This number is considered very low, and therefore is unable to efficiently cater to $\mathrm{MNH}$ services. The situation further worsens as these LHVs are spread across the country. Moreover, a high proportion prefer to work in the private sector, leaving a very small number providing services to people in the rural areas (Bhutta et al. 2004).

Currently, these LHVs work as static care providers because of the issues related to logistics at the district level. The dai or traditional birth attendant is predominantly the other main provider. She is not formally trained, rather learns her skills from her elders and usually the profession runs in families. Being a local resident, she is well-respected and trusted in the community. Due to lack of formal training, she usually does not follow the clean delivery practices and delays referrals when needed. The Lady Health Worker (LHW) is also a public sector community based worker but is not involved in conducting deliveries. She is supposed to provide health education sessions and motivate the women for antenatal check up from a trained care provider. She records the history of pregnant women and assesses the severity of any condition; in case of problems she refers her client/patient to a health facility. 
Women living in the rural areas do not have access to services of skilled birth attendants (SBAs). They have no other option but to get obstetrical services from dais. If a care provider is introduced in the community with formal training, fulfilling the requirements of an SBA, then it can be assumed that women in rural areas may get better obstetrical services. A community midwife (CMW) is the new cadre being proposed by the Ministry of Health $(\mathrm{MoH})$, who will be trained for 18 months and then will be placed in the community of her residence. It is expected that she will be able to fill in the existing gaps in services provided by the three care providers i.e.; LHV, LHW and a dai. A qualitative research study carried out by the Population Council also provides the opinion of the women and men who want such type of care providers in their communities (Wajid et al., 2010).

\subsection{PAIMAN}

The Pakistan Initiative for Mothers and Newborns (PAIMAN) project, funded by United States Agency for International Development (USAID), is assisting the Government of Pakistan (GoP) to employ the full range of interventions necessary to address mother and newborn health. The PAIMAN project will directly contribute to reducing maternal and newborn mortality in Pakistan through feasible and demonstrable initiatives. These comprise capacity building of structures and existing programs within health systems and communities and ensuring improvements and supportive linkages of health care for women from home to hospital. One of the project's main objectives is to increase community-based access to $\mathrm{MNH}$ services through training and placement of community midwives.

The key activity at the heart of PAIMAN's long-term goal of reducing the incidence of maternal and newborn mortality is a skilled birth attendant strategy. PAIMAN has been very active in drafting, advocating, finalizing and putting into operation the National Skilled Birth Attendant (SBA) strategy, which has become an integral part of the National Program on Maternal, Newborn and Child Health (MNCH). Access to a skilled birth attendant is required throughout pregnancy, childbirth and the postpartum period in order to decrease the maternal and newborn mortality. In most of the rural areas of Pakistan, however, skilled birth attendants are not available.

To enhance coverage of services by skilled birth attendants, especially in the rural areas, the GoP decided to introduce a new cadre of community midwives. To provide training to 
these community midwives (CMWs), it was recommended that 97 new midwifery schools be constructed. The training of CMWs has now commenced all over Pakistan. Training is designed to last for 18 months: course work is completed during the first 12 months, followed by placement of CMWs in their respective communities for hands-on training under the supervision of LHVs/Woman Medical Officers (WMOs) present in the attached health facility. The selection of CMWs is based on the following criteria (Ministry of Health 2006):

- Female, preferably married

- Aged 18-35 years

- Permanent resident of the area from which she is applying

- Minimum qualification should be at least matric with at least 45 percent marks in science subjects

- Experience of working in the community.

It is required that each CMW should possess a minimum level of skills for conducting deliveries. To achieve the prescribed level of expertise, the Pakistan Nursing Council recommends that each community midwife have done the following (PNC 2005):

- Observe 5 normal deliveries

- Assist at 5 normal deliveries

- Conduct 5 normal deliveries under supervision

- Conduct 10 normal deliveries independently.

After successful completion of course work and hands-on training, each CMW is appointed in her designated community/union council covering a population of 5000. The locally resident LHW of the National Program for Family Planning and Primary Health Care is expected to be helping the CMWs in registering eligible women for obstetrical services. The CMWs are provided with the required supplies/logistics to establish her midwifery house (Ministry of Health 2006). The tutors of these CMWs are responsible for the supervision of these CMWs in the community. The Pakistan Nursing Council is the overall regulatory and licensing body. The Council is charged with monitoring the practice of CMWs and renewing their licenses after two years (Ministry of Health 2006).

These CMWs will be provided with an honorarium of Rs. 2000 per month, along with a training allowance of Rs. 1500 during institutional (course work) and practical training. To 
support them during the initial period after training, an amount of Rs. 2, 000 per month will be paid while they are practicing in their communities (Ministry of Health 2006).

\subsection{Study Rationale}

The GoP and PAIMAN, along with its partners, have spent a considerable period of time in identifying suitable training institutes to train the midwifery students and an effort was made to equip them with the best knowledge and practical skills. The vision of this program is to provide women, especially those in rural areas, with the services of community midwives to provide easily accessible maternity care. The success of these efforts will be evaluated after allowing a considerable time period as the program is currently in its initial phase. In this study, an effort has been made to appraise the training, supervision, knowledge and practical skills of CMWs.

Community midwifery services in the main provide continuity of midwifery-led care to women throughout the childbearing cycle, in collaboration with other practitioners, such as general practitioners, specialist obstetricians and dais, where indicated. Therefore, in this survey potential barriers to the placement of CMWs were also explored. This study was a great opportunity to evaluate the competencies of CMWs in the six selected districts, and to provide baseline information on different aspects related to training and community placement of CMWs.

\subsection{Study Objectives}

The goal of this study was to assess the community midwifery services in rural Pakistan in order to provide necessary evidence for future decisions regarding the training, practice and placement of community midwives. 
The specific objectives of the study were:

1. To appraise the training and supervision of CMWs.

2. To determine knowledge and skills of CMWs.

3. To explore barriers to the placement of CMWs in the community.

4. To provide suggestions for scaling up the midwifery program.

\subsection{Methodology}

This research activity was carried out as a component of an operations research (OR) project looking at the acceptability of a new cadre of community midwives for pregnancy and delivery-related care in rural Pakistan. In the first phase of the OR project, a qualitative study was conducted to assess the potential acceptability of CMWs before their placement in the communities. In this second phase, information was obtained following an exploratory study design as some information was collected retrospectively, especially for the course work and practical training, while some information was obtained about current knowledge.

\section{Sample}

For this phase of the operation research study, those batches of midwives were selected who had completed their course work and had successfully passed the examination before the start of the study. There were batches of midwives in six districts (Rawalpindi, Jhelum, Khanewal, Dera Ghazi Khan [D.G. Khan], Dadu and Sukkur) who had taken their examinations either in the second half of 2008 or the first quarter of 2009 and had passed. All of those midwives who were willing to be part of the operations research study and had passed their examinations were included in this study.

There were 174 midwives who were going to take their final examination after AugustSeptember 2008 in the above mentioned six districts. All were verified for their residential status. Out of these, 43 were found non-resident and 16 could not successfully pass their examinations. Out of the remaining $115 \mathrm{CMWs}$, PAIMAN provided equipment to 109 to establish their midwifery homes (MWH) in September 2009. Three CMWs were further removed from the list as two shifted from Dadu to Hyderabad and refused to establish a MWH, while one from D.G. Khan belonged to a tribal area that was 
inaccessible for interviewing. Finally, a total of 106 midwives were contacted for interviews in the six districts. (See Figure 1.)

Figure 1: Schematic diagram showing sampling of CMWs

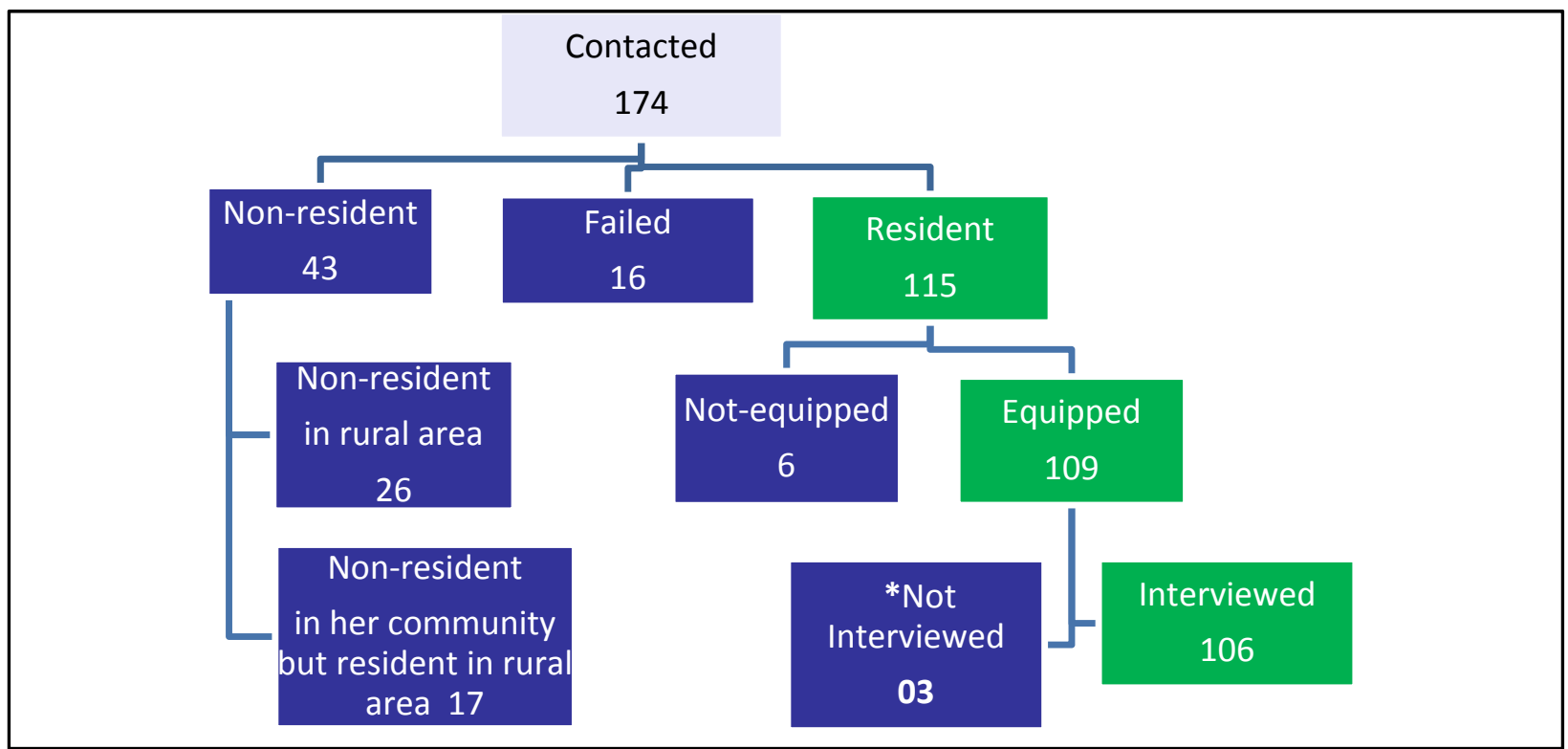

*2 shifted from Dadu to Hyderabad and refused to establish the MWH; 1 from D.G. Khan was not accessible due to tribal area

\section{Questionnaire}

The questionnaire for this research activity consisted of two main sections. The first included questions on background characteristics, training, knowledge about maternal and newborn health and community placement of midwives after training. The second section focused on skill assessment regarding routine and important practical tasks, such as assessment of anemia, abdominal examination, use of clean delivery kit, hand washing, process of delivery of a newborn, cleanliness of a newborn and examination of cord and placenta.

\section{Ethical considerations}

Ethical approval was obtained from the institutional review board (IRB) at the Population Council's headquarters in New York. The steps taken to ensure that the study met all ethical considerations are described below. 


\section{Informed consent}

Informed consent was obtained from all study participants after describing to them in detail the issues related to the study. For the structured questionnaire, the LHV interviewers described the scope and purpose of the questionnaire and its approximate length, and they stressed that participation was entirely voluntary. The confidentiality of all responses was stressed.

\section{Privacy}

The structured questionnaires were conducted in private and out of the hearing of other people. For the practical observation section, adequate auditory and visual privacy was ensured.

\section{Confidentiality}

All data collected for the study were kept confidential and anonymous. The structured questionnaires were identified by personal identification codes rather than participant names. All respondents were ensured that the results will be kept confidential and anonymous.

\section{Interviewers}

Each interviewing team recruited for one district comprised a logistic supervisor and a lady health visitor (LHV). The LHVs were trained in interviewing the midwives, making observations about the $\mathrm{MWH}$, if possible, and assessing the performance of each CMW for her ability to carry out different tasks.

\section{Training and field work}

The interviewers received seven days of training in August 2009 conducted by the Population Council. The training included sessions on the research protocol, ethics, obtaining informed consent, maintaining privacy during the interview process, sampling methodology, interviewing techniques and practical skills. Numerous role-play sessions were conducted as part of the questionnaire training. The training stressed the importance of respecting respondents and adopting a nonjudgmental attitude throughout the interview. One day of pretesting in the field was included and allowed for individual feedback for each interviewer. The interviewers were informed about zero 
tolerance for any moral or ethical dishonesty and the importance of maintaining confidentiality of the information they obtained. Field work was conducted from August 2009 to September 2009.

\section{Quality control}

To ensure the maintenance of the highest quality standards in both data collection and data analysis, a number of measures were instituted. These measures are described below.

\section{Roles and responsibilities}

Roles and responsibilities of each team member were clearly identified. Each member was provided with a written set of responsibilities that they were required to follow.

\section{Monitoring}

During fieldwork, the principal investigator and a public health physician (both from the Population Council) regularly visited each study site. They randomly selected and visited the study sites to ensure that all protocols were being followed. During these visits, the monitors also randomly selected completed questionnaires to check for completeness and accuracy.

\section{Data management}

The logistics supervisors sent the completed questionnaires to the Population Council office in Islamabad. Prior to commencing data entry, the questionnaires were edited. The data were then coded and entered into the computer using CSPro (version 4.1). To minimize errors and omissions the data entry program was developed with range skips and filter checks. SPSS (version 16.0) was used for quantitative data analysis. All study data and forms were stored in locked cabinets at the Population Council office in Islamabad. 


\section{Findings}

In this section, the results of the study are presented. This information includes the characteristics of the community midwives, their training, placement, knowledge on key maternal and newborn health issues, placement in communities and, finally, their plans and expectations. As stated earlier, with some questions, the midwives were asked about past experiences and in some they were talking about current issues and in some they discussed future events.

\subsection{Characteristics}

All of the midwives were asked about specific characteristics, which included age, education, marital status, language spoken in the household and work other than midwifery.

\section{Age}

Slightly less than half of the sample (48 CMWs) was in the age range of 20-24 years, with the next largest group aged 25-29 years (23 CMWs). The mean age of the $106 \mathrm{CMWs}$ was 25 years. (See Figure 2.)

Figure 2: Percentage distribution of community midwives, by age group

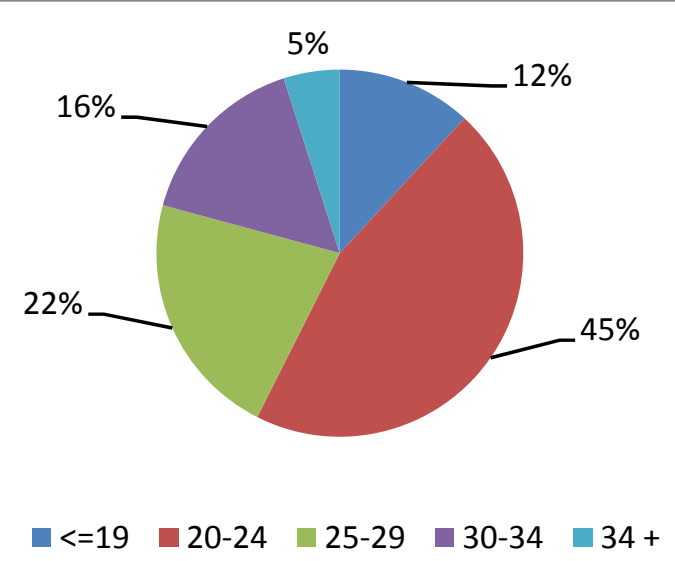

In districts Jhelum, Khanewal, D.G. Khan and Dadu, a comparatively higher proportion of younger midwives was found. In Rawalpindi, the CMWs were more evenly distributed across the five age groups. 
Initially, the age requirement for a female to be admitted as a CMW student was fixed at 19 years and above; however, the Pakistan Nursing Council (PNC) revised this to 18 years of age and above. All of the CMWs who were interviewed were 18 years or older.

\section{Marital status}

One-third of the CMWs (35 out of 106) were married, just under two-thirds (69) were single, and the remaining 2 midwives were widowed or divorced (Figure 3). A relatively higher proportion of midwives in Rawalpindi (13/19), D.G. Khan (8/14) and Sukkur (5/7) were married, while a higher number of CMWs (34/39) were single in Dadu.

\section{Education}

Figure 4 shows the educational status of the CMWs. As grade 10 has been set as the minimum level of education required for the recruitment of a CMW, all midwives fulfilled this criterion. D.G. Khan was among the districts where comparatively more midwives had completed their education up to grade 14.

Figure 3: Percentage distribution of community midwives, by marital status

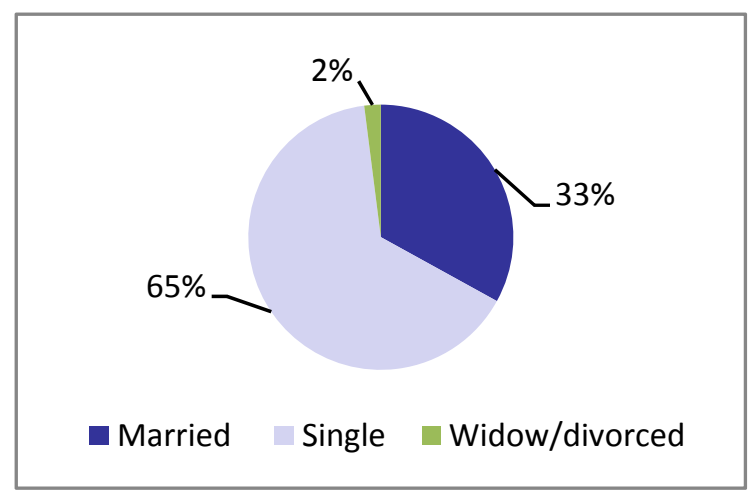

Figure 4: Percentage distribution of community midwives, by years of education

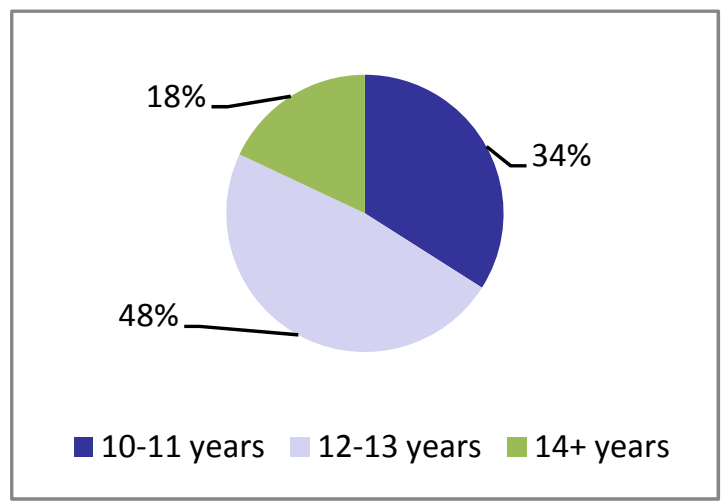

\section{Language}

Overall, Punjabi was the most commonly spoken language (36 percent), closely followed by Sindhi (32 percent) (Figure 5). About one-fifth of the midwives were Saraikie speaking while very few of the CMWs came from Urdu or Potohari speaking families. 
Figure 5: Percentage distribution of community midwives, by language spoken in their households

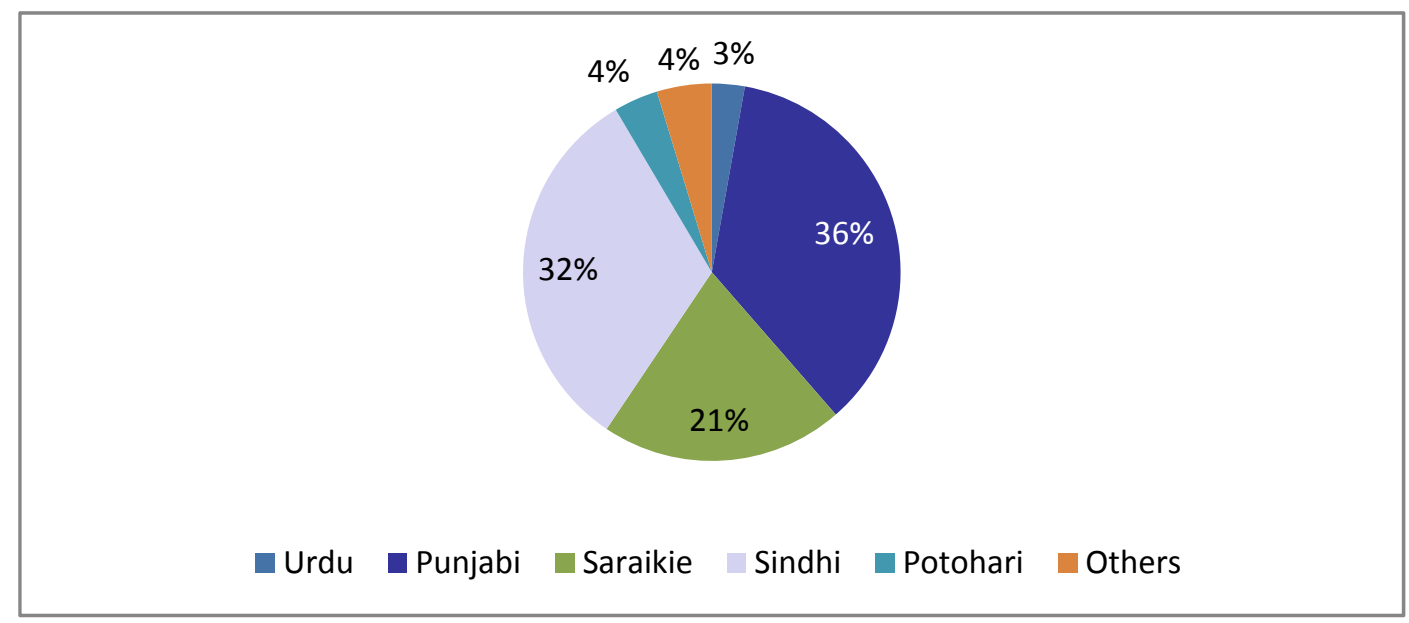

\section{Other paid work}

There were only 17 midwives who stated that they were doing work in addition to their midwifery practice. Of these, some were involved in teaching, while others utilized their skills of stitching and embroidery.

\subsection{Training}

PAIMAN initiated training of midwives at different time intervals in various districts. In the six study districts, midwives took their final examinations after August 2008, so they were ready to be placed in their community and to establish their midwifery home at the time of their participation in the study.

Of the community midwives in the study, 88 percent had completed their training in 2008 and 7 percent in 2009. The remaining 5 percent were not able to exactly recall the information. The total duration of training reported by all midwives was 18 months divided into two main phases: school and hospital based training for 15 months and community based training for 3 months.

\section{Deliveries}

One of the prime objectives of a CMW program is to bring a skilled birth attendant (SBA) closer to rural communities that cannot easily access the services of existing SBAs. To achieve this objective, it was necessary that these CMWs not only learn the basic principles of conducting a delivery but also learn how to actually conduct a delivery. 
During the course work and practical training, arrangements were made by the respective nursing/public health schools for the student midwives to observe the actual process of delivery and care of newborns and, afterwards, conduct deliveries themselves. To follow the protocol, the midwives students first observed a certain number of deliveries. Then they conducted deliveries under the supervision of a lady health visitor or a woman medical officer in a health facility.

Overall, half of these midwives conducted 15 or more deliveries during their training period (Figure 6). All but one midwife in Rawalpindi and 9 out of 10 midwives in Jhelum conducted 15 or more deliveries. On the other hand, only 2 out of 14 midwives in D.G. Khan and 4 out of 17 in Khanewal were able to reach that level of practice. Similarly, the situation in Dadu and Sukkur also did not reach the level of Rawalpindi and Jhelum: 16 out of 39 midwives from Dadu and 4 out of 7 from Sukkur conducted 15 or more deliveries during their training.

Figure 6: Percentage of community midwives who conducted 15 or more deliveries during training, by district

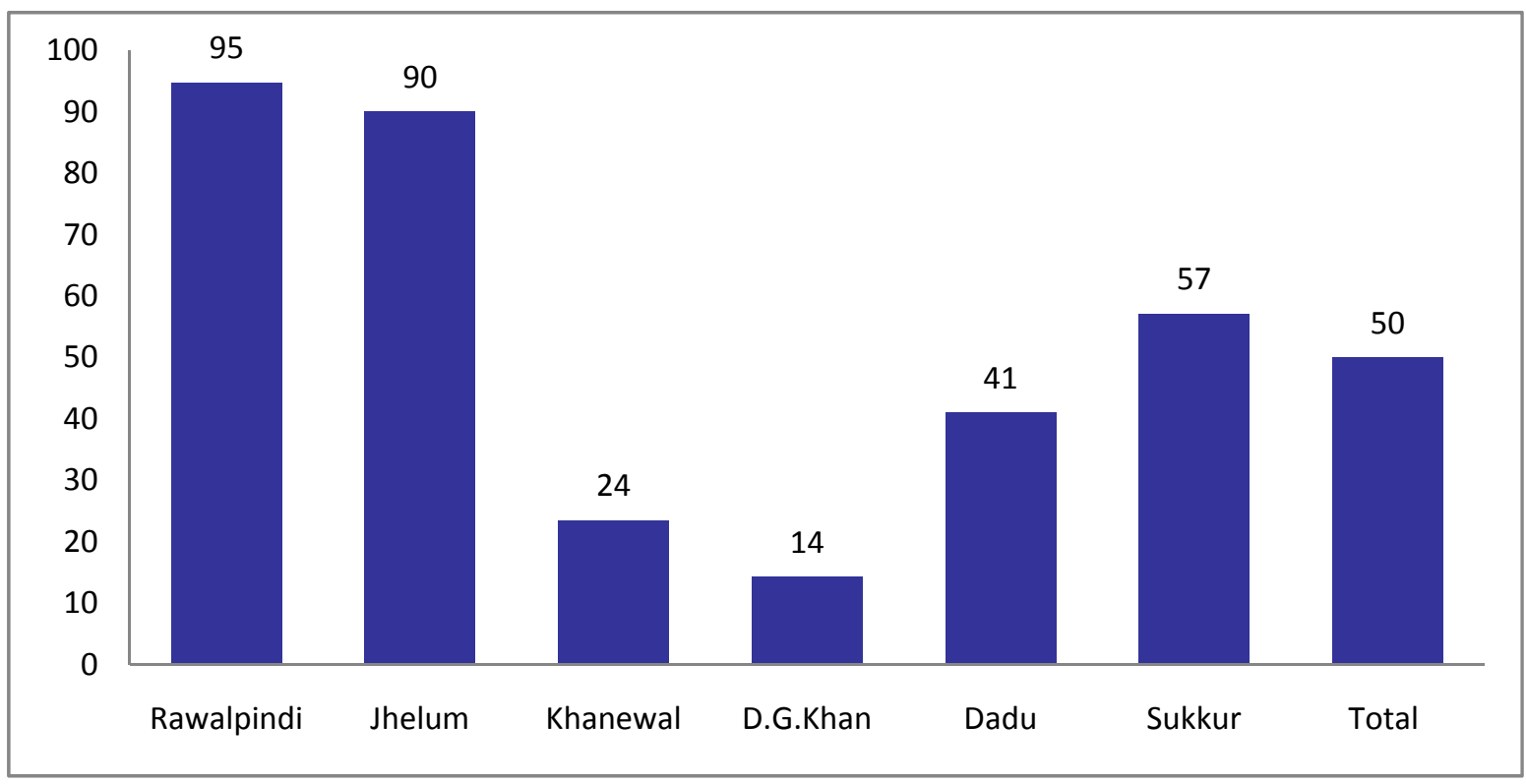

Of the total sample, 18 midwives conducted only 5 or fewer deliveries; this includes 8 from Khanewal and 6 each from D.G. Khan and Dadu. None of the six districts could completely fulfill the PNC standard that there be a minimum of 15 or more deliveries conducted during each CMW's training. 
A cross-tabulation was carried out between the age of midwives and the number of deliveries conducted. As shown in Figure 7, CMWs who were older than 24 years of age were more likely to conduct 15 or more deliveries when compared to the younger age group. This difference was found to be statistically significant at .05 level ( $p$.01).

Similarly, we also looked at the level and pattern of association between marital status and number of deliveries conducted by CMWs (Figure 7). A higher proportion of married midwives conducted more deliveries as compared to unmarried ones; however, the difference was not statistically significant at .05 level.

Figure 7: Percentage distribution of community midwives, by number of deliveries conducted, by age and marital status

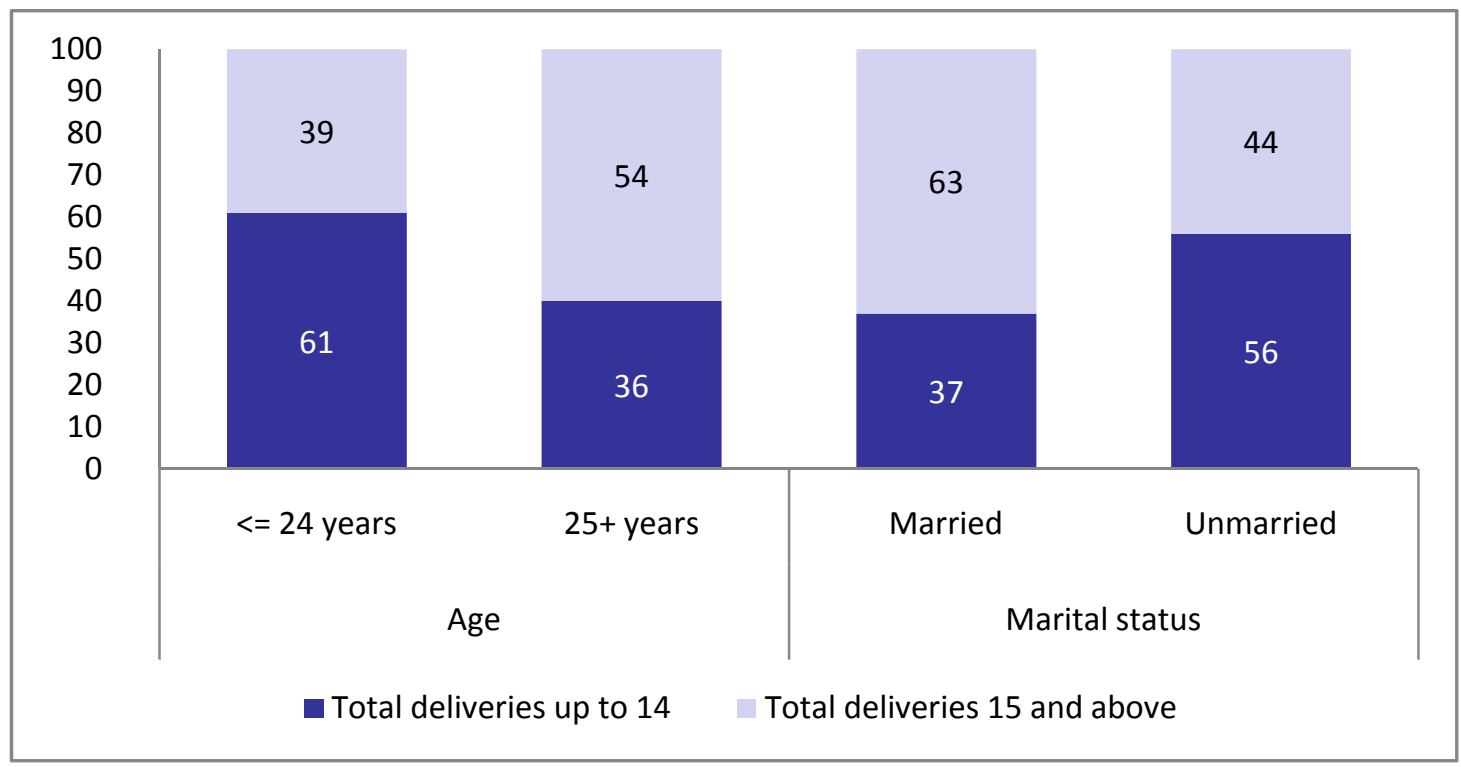

\section{Problems}

During the training period, the student midwives were provided an opportunity to work in a rural area under the supervision of either their trainers or some senior staff members of the health facility (LHVs or WMOs). The purpose of this activity was to help the midwives understand the community environment and learn to perform practical tasks, including deliveries, within a rural setting. Just over a quarter of the midwives (28/106) experienced some problem during their community-placement phase.

The most frequently reported problems were deficient or inappropriate introduction to the community upon their initial placement and their young age (Figure 8). Out of the total midwives, 11 stated each of these problems. The next most frequent response was 
related to interpersonal communication (7 CMWs). In most cases these problems were addressed. The most frequently cited person who intervened to resolve the issues was the CMW's supervisor, followed by the local health care provider.

Figure 8: Percentage of community midwives who reported specific problems during community training

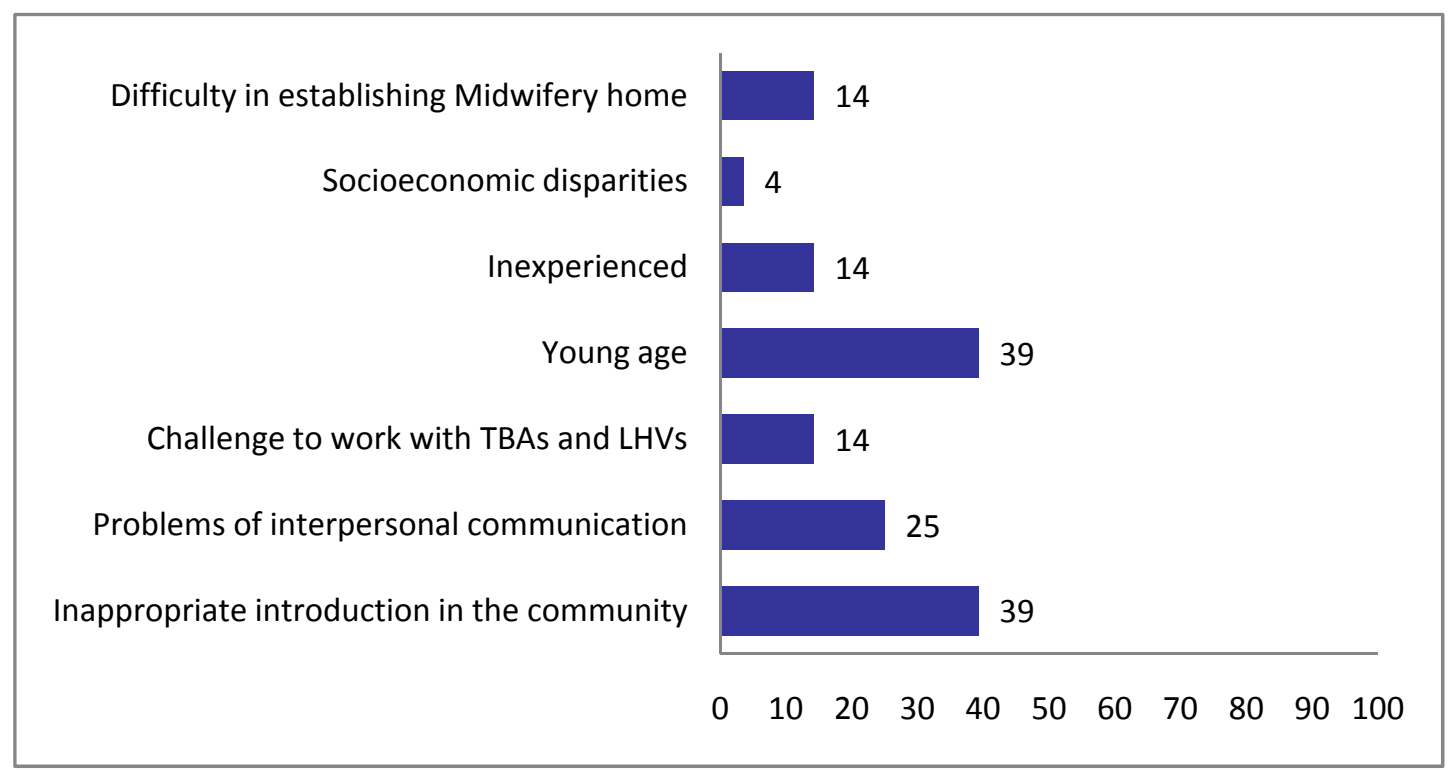

Note: Multiple responses were possible.

\subsection{Knowledge: Maternal Health}

The knowledge of CMWs was assessed on different aspects of maternal health. For assessing the knowledge of danger signs of pregnancy, delivery and postpartum period, the CMWs were first asked specific knowledge-based questions derived from their curriculum. First, spontaneous responses were received and this was followed by responses that were obtained upon prompting. The topics which were assessed for knowledge included: management of eclampsia, process of labor, obstetrical complications requiring referral, and management of puerperal sepsis.

\section{Danger signs of pregnancy}

Information was collected and analyzed on the following five danger signs of pregnancy: high blood pressure, heavy vaginal bleeding, blurring of vision, severe abdominal pain, and fits or convulsions. 
Table 1 shows that knowledge of danger signs varied across districts. CMWs from Sukkur, Jhelum and Dadu were more aware of danger signs as compared to other districts. The majority of respondents mentioned heavy vaginal bleeding and high blood pressure. All $\mathrm{CMWs}$ in Jhelum were aware of these two danger signs. Knowledge regarding blurring of vision and severe abdominal pain was very limited across all districts: only 5 CMWs mentioned blurring of vision and $9 \mathrm{CMWs}$ mentioned severe abdominal pain. It is important to note that blurring of vision was not mentioned by any of the respondents in Rawalpindi, Khanewal or D.G. Khan; likewise, severe abdominal pain was not mentioned by any of the respondents in Rawalpindi and Khanewal.

Table 1: Number of community midwives who spontaneously named specific danger signs of pregnancy, by district

\begin{tabular}{lrrrrrrr}
\hline Danger sign & Rawalpindi & Jhelum & Khanewal & D.G. Khan & Dadu & Sukkur & Total \\
\hline High BP & 16 & 10 & 15 & 8 & 27 & 6 & 82 \\
\hline Heavy vaginal bleeding & 13 & 10 & 13 & 11 & 33 & 6 & 86 \\
\hline Blurring of vision & 0 & 1 & 0 & 0 & 3 & 1 & 5 \\
\hline Severe abdominal pain & 0 & 1 & 0 & 2 & 2 & 4 & 9 \\
\hline Fits or convulsions & 5 & 5 & 0 & 3 & 20 & 5 & 38 \\
\hline Total respondents & $\mathbf{1 9}$ & $\mathbf{1 0}$ & $\mathbf{1 7}$ & $\mathbf{1 4}$ & $\mathbf{3 9}$ & $\mathbf{7}$ & $\mathbf{1 0 6}$ \\
\hline
\end{tabular}

Note: Multiple responses possible.

- 30 percent of midwives spontaneously knew three or more danger signs of pregnancy.

- 3 percent of midwives did not know any danger signs of pregnancy.

- No midwife knew all of the danger signs of pregnancy.

\section{Danger signs of delivery}

Information was collected and analyzed on the following danger signs of delivery: premature rupture of membranes, prolonged labor, retained placenta, excessive vaginal bleeding and mal positioning of fetus.

Table 2 shows that 88 respondents mentioned excessive vaginal bleeding as an important danger sign of delivery. All of the respondents from Sukkur knew about premature rupture of membrane, while in D.G. Khan none of the CMWs was aware of this. About two-thirds of the respondents in Jhelum and Sukkur were aware of prolonged labor (6/10 and 5/7 respectively). Overall the knowledge of all other danger signs was very limited across all districts. 
Table 2: Number of community midwives who spontaneously named specific danger signs of delivery correctly, by district

\begin{tabular}{lrrrrrrr}
\hline Danger sign & Rawalpindi & Jhelum & Khanewal & D.G. Khan & Dadu & Sukkur & Total \\
\hline $\begin{array}{l}\text { Premature rupture of } \\
\text { membranes }\end{array}$ & 6 & 2 & 3 & 0 & 22 & 7 & 40 \\
\hline Prolonged labor & 6 & 7 & 6 & 3 & 19 & 5 & 46 \\
\hline Retained placenta & 6 & 5 & 1 & 5 & 12 & 4 & 33 \\
\hline Excessive vaginal bleeding & 16 & 7 & 14 & 13 & 33 & 5 & 88 \\
\hline Mal positioning of fetus & 2 & 4 & 5 & 6 & 14 & 3 & 34 \\
\hline Total respondents & $\mathbf{1 9}$ & $\mathbf{1 0}$ & $\mathbf{1 7}$ & $\mathbf{1 4}$ & $\mathbf{3 9}$ & $\mathbf{7}$ & $\mathbf{1 0 6}$ \\
\hline
\end{tabular}

Note: Multiple responses possible.

- 42 percent of midwives knew at least three danger signs of delivery.

- 3 percent of midwives did not know any danger signs of delivery.

- No midwife knew all of the danger signs of delivery.

\section{Eclampsia}

Eclampsia is defined as the occurrence of convulsions not caused by any coincidental neurological disease such as epilepsy in a woman whose condition also meets the criteria for preeclampsia (Mordechai 1999). Knowledge of CMWs was assessed regarding management of eclampsia because prompt recognition and referral plays an important role in the management of the patient.

Table 3 shows that a majority of respondents ( $90 \mathrm{CMWs)} \mathrm{mentioned} \mathrm{referring} \mathrm{a} \mathrm{patient} \mathrm{to}$ a higher-level facility in order to manage a patient with eclampsia. It is important to note that only a small number of respondents mentioned the basic management that is required to stabilize the patient prior to referral, which includes management of airway, breathing and circulation. None of the respondents mentioned management of breathing in Jhelum and Sukkur; no midwife mentioned management of circulation in Rawalpindi, Khanewal, D.G. Khan and Sukkur. 
Table 3: Number of community midwives who correctly knew specific components for managing eclampsia, by district

\begin{tabular}{lrrrrrrr}
\hline Component & Rawalpindi & Jhelum & Khanewal & D.G. Khan & Dadu & Sukkur & Total \\
\hline Manage airway & 10 & 2 & 2 & 1 & 20 & 7 & 42 \\
\hline Manage breathing & 2 & 0 & 0 & 1 & 10 & 0 & 13 \\
\hline Manage circulation & 0 & 1 & 0 & 0 & 6 & 0 & 7 \\
\hline $\begin{array}{l}\text { Magnesium sulphate } \\
\text { IV }\end{array}$ & 4 & 0 & 1 & 0 & 13 & 1 & 19 \\
\hline Referral & 17 & 9 & 16 & 10 & 31 & 7 & 90 \\
\hline Don't know & 1 & 0 & 1 & 4 & 0 & 0 & 6 \\
\hline Total respondents & $\mathbf{1 9}$ & $\mathbf{1 0}$ & $\mathbf{1 7}$ & $\mathbf{1 4}$ & $\mathbf{3 9}$ & $\mathbf{7}$ & $\mathbf{1 0 6}$ \\
\hline
\end{tabular}

Note: Multiple responses possible.

- 20 percent of midwives knew three steps of eclampsia management.

- 6 percent of midwives did not know any steps of eclampsia management.

- No midwife knew all steps of eclampsia management.

\section{Labor and delivery}

Childbirth can be a time of great risk for both mother and newborn. The knowledge of respondents was assessed on different important aspects of labor and delivery, including: prevention of infection during delivery, use of the partograph, vaginal examination, management of prolonged labor, and active management of the third stage of labor (AMTSL).

\section{Infection prevention}

Infection prevention during labor and delivery is a basic and crucial step in safeguarding the lives of mothers and newborns. Infections after birth, especially infections of the birth canal, can be grave and can lead to death; therefore, it is imperative that midwives take firm measures to protect mothers and newborns against infections.

Table 4 shows the knowledge of midwives on different steps of infection prevention. More than three-fourths of respondents were aware of maintenance of general hygienic conditions, use of protective clothing and gloves, and cleaning of instruments $(91,94$, and 84 respectively). In Dadu and Sukkur, all of the CMWs mentioned maintenance of general hygienic conditions; in Jhelum, 9 midwives knew about this. Likewise, all CMWs in Sukkur and Jhelum were aware of the need to use protective clothing, gloves and clean instruments; almost all in Dadu (38/39) were aware of both of these steps. Half of all 
respondents (53) had knowledge of decontamination of instruments; however, in D.G. Khan and Khanewal none of the CMWs had knowledge of this step. Slightly more than half of the respondents mentioned sterilization and disinfection. Across all districts none of the CMWs mentioned proper handling and disposal of sharps.

Table 4: Number of community midwives who correctly knew specific steps in infection prevention, by district

\begin{tabular}{|c|c|c|c|c|c|c|c|}
\hline Step & Rawalpindi & Jhelum & Khanewal & D.G. Khan & Dadu & Sukkur & Total \\
\hline $\begin{array}{l}\text { Maintenance of general hygiene } \\
\text { conditions }\end{array}$ & 15 & 9 & 13 & 8 & 39 & 7 & 91 \\
\hline $\begin{array}{l}\text { Use of protective clothing and } \\
\text { gloves }\end{array}$ & 18 & 10 & 10 & 11 & 38 & 7 & 94 \\
\hline Cleaning of instruments & 16 & 10 & 6 & 7 & 38 & 7 & 84 \\
\hline Decontamination of instruments & 8 & 3 & 0 & 0 & 36 & 6 & 53 \\
\hline $\begin{array}{l}\text { Sterilization and high-level } \\
\text { disinfection }\end{array}$ & 9 & 7 & 4 & 2 & 33 & 6 & 61 \\
\hline Proper storage of instruments & 0 & 1 & 1 & 0 & 2 & 1 & 5 \\
\hline $\begin{array}{l}\text { Proper handling and disposal of } \\
\text { sharps }\end{array}$ & 2 & 0 & 1 & 0 & 0 & 0 & 3 \\
\hline Don't know & 0 & 0 & 0 & 1 & 0 & 0 & 1 \\
\hline Total respondents & 19 & 10 & 17 & 14 & 39 & 7 & 106 \\
\hline
\end{tabular}

Note: Multiple responses possible.

- 47 percent of midwives knew at least 5 steps of infection prevention during delivery.

- 1 percent of midwives did not know any steps of infection prevention during delivery.

- No midwife knew all of the steps of infection prevention during delivery.

\section{Partograph}

A partograph is used for the assessment of the progress of labor. Findings are plotted on a graph commencing at the start of the active phase of labor. The graph has four basic components: 1) patient information, 2) fetal condition, 3) progress of labor, and 4) maternal condition. Midwives are supposed to have knowledge of all of these components in order to assess the progress of labor and to make timely decisions regarding referrals, if needed.

Table 5 shows the knowledge of respondents on the different components of a partograph. A majority of respondents mentioned the third component of a partograph (progress of labor), which is the most important component of a partograph. All of the 
CMWs in Rawalpindi and Jhelum were knowledgeable about the third component of a partograph; the lowest response was in D.G. Khan (11 out of 14). Seventy-five respondents had knowledge of each of the first two components of a partograph (patient information and fetal condition). The component mentioned the least was maternal condition, mentioned by only 31 respondents.

Table 5: Number of community midwives who correctly knew specific components of a partograph, by district

\begin{tabular}{|c|c|c|c|c|c|c|c|}
\hline Component & Rawalpindi & Jhelum & Khanewal & D.G. Khan & Dadu & Sukkur & Total \\
\hline Patient information & 8 & 7 & 12 & 5 & 37 & 6 & 75 \\
\hline Fetal condition & 16 & 9 & 7 & 5 & 33 & 5 & 75 \\
\hline Progress of labor & 19 & 10 & 15 & 11 & 33 & 6 & 94 \\
\hline Maternal condition & 9 & 2 & 5 & 7 & 7 & 1 & 31 \\
\hline Don't know & 0 & 0 & 1 & 0 & 1 & 1 & 3 \\
\hline Total respondents & 19 & 10 & 17 & 14 & 39 & 7 & 106 \\
\hline
\end{tabular}

Note: Multiple responses possible.

- 74 percent of midwives knew at least 3 components of a partograph.

- 3 percent of midwives did not know any components of a partograph.

- No midwife knew all components of a partograph.

\section{Vaginal examination}

Vaginal examination is used to assess cervical dilatation and the descent of the fetal head. The findings of a vaginal examination are plotted on a partograph for assessment of the progress of labor. The different aspects of a vaginal examination on which information was collected and analyzed included frequency of vaginal examination, use of disposable gloves and frequency of usage. When monitoring the first stage of labor it is recommended not to undertake a vaginal examination less than every four hours, unless there is some other indication. Table 6 shows that only $22 \mathrm{CMWs}$ had the correct knowledge regarding frequency of a vaginal examination, while $46 \mathrm{CMWs}$ mentioned that a vaginal examination should be performed after two hours. 
Table 6: Number of community midwives, by response on frequency for vaginal examinations, according to district

\begin{tabular}{lrrrrrrr}
\hline Frequency (in hours) & Rawalpindi & Jhelum & Khanewal & D.G. Khan & Dadu & Sukkur & Total \\
\hline 0 & 0 & 0 & 0 & 7 & 0 & 0 & 7 \\
\hline 1 & 5 & 1 & 9 & 2 & 6 & 1 & 24 \\
\hline 2 & 8 & 5 & 5 & 3 & 20 & 5 & 46 \\
\hline 3 & 1 & 0 & 0 & 1 & 2 & 0 & 4 \\
\hline 4 & 4 & 3 & 2 & 1 & 11 & 1 & 22 \\
\hline 6 & 1 & 1 & 1 & 0 & 0 & 0 & 3 \\
\hline Total respondents & $\mathbf{1 9}$ & $\mathbf{1 0}$ & $\mathbf{1 7}$ & $\mathbf{1 4}$ & $\mathbf{3 9}$ & $\mathbf{7}$ & $\mathbf{1 0 6}$ \\
\hline
\end{tabular}

Note: Multiple responses possible.

\section{Disposable gloves}

When asked about the practice of using disposable gloves for vaginal examinations, it was found that all but one midwife were observing this practice. The one exception was in Jhelum. As for frequency of use of disposable gloves, 103 respondents reported that they used disposable gloves every time they did a vaginal examination. All of the CMWs from Khanewal, D.G. Khan, Dadu, and Sukkur used disposable gloves every time they did a vaginal examination; only $1 \mathrm{CMW}$ in Jhelum and 1 in Rawalpindi said that they "mostly" used disposable gloves.

\section{Prolonged labor}

Prolonged labor is defined as labor of more than 24 hours in a primigravida and labor of more than 14 hours in a multigravida. Midwives had been trained to recognize and manage prolonged labor. Only 15 respondents mentioned both components of the definition (Table 7). None of the respondents from Rawalpindi, Dadu and Sukkur, and only 1 from D.G. Khan, mentioned both parts of the definition; however, almost all of the midwives from Jhelum mentioned both factors (9 out of 10). 
Table 7: Number of community midwives who correctly knew specific factors in identifying prolonged labor, by district

\begin{tabular}{|c|c|c|c|c|c|c|c|}
\hline Factor & Rawalpindi & Jhelum & Khanewal & D.G. Khan & Dadu & Sukkur & Total \\
\hline $\begin{array}{l}\text { Mentioned only labor of }>24 \\
\text { hrs in primigravida }\end{array}$ & 1 & 0 & 2 & 1 & 22 & 5 & 31 \\
\hline $\begin{array}{l}\text { Mentioned only labor of }>14 \\
\text { hrs in a multipara }\end{array}$ & 0 & 0 & 0 & 0 & 1 & 0 & 1 \\
\hline $\begin{array}{l}\text { Mentioned both of the above } \\
\text { factors }\end{array}$ & 0 & 9 & 5 & 1 & 0 & 0 & 15 \\
\hline Others & 16 & 1 & 10 & 10 & 1 & 0 & 38 \\
\hline Don't know & 2 & 0 & 0 & 2 & 15 & 2 & 21 \\
\hline Total respondents & 19 & 10 & 17 & 14 & 39 & 7 & 106 \\
\hline
\end{tabular}

When asked about the management of prolonged labor, a majority of the CMWs (96) mentioned referral; all CMWs from Jhelum, Khanewal and Sukkur mentioned this, as did 18 of 19 from Rawalpindi (Table 8). Only 21 respondents mentioned use of IV fluids; none of the midwives from Jhelum mentioned this. Use of oxytocin for acceleration of labor was mentioned by 20 respondents. Though all of the CMWs in Jhelum mentioned referral, none of them mentioned any other management factors for prolonged labor. Caesarian section was mentioned by 7 midwives; among these, 6 were from Dadu and 1 from Sukkur. Only 6 midwives, all from Dadu, mentioned the use of antibiotics.

Table 8: Number of community midwives who correctly knew specific factors in managing prolonged labor, by district

\begin{tabular}{lrrrrrrr}
\hline Factors & Rawalpindi & Jhelum & Khanewal & D.G. Khan & Dadu & Sukkur & Total \\
\hline IV fluids & 3 & 0 & 1 & 3 & 12 & 2 & 21 \\
\hline Antibiotics & 0 & 0 & 0 & 0 & 6 & 0 & 6 \\
\hline $\begin{array}{l}\text { Acceleration of labor by } \\
\text { oxytocin }\end{array}$ & 3 & 0 & 3 & 10 & 3 & 1 & 20 \\
\hline Caesarian section & 0 & 0 & 0 & 0 & 6 & 1 & 7 \\
\hline Referral & 18 & 10 & 17 & 9 & 35 & 7 & 96 \\
\hline Don't know & 0 & 0 & 0 & 0 & 1 & 0 & 1 \\
\hline Total respondents & 19 & 10 & 17 & 14 & 39 & 7 & 106 \\
\hline Note: Multiple respon
\end{tabular}

Note: Multiple responses possible. 
- 13 percent of midwives knew at least 3 steps of prolonged labor management.

- 1 percent of midwives did not know any steps of prolonged labor management.

- No midwife knew all 5 steps of prolonged labor management.

\section{Active management of 3rd stage of labor}

All midwives should be able to carry out active management of the third stage of labor (AMTSL); otherwise, grave complications can arise, such as hemorrhage and inversion of the uterus. Active management of the third stage of labor also plays a considerable role in the prevention of postpartum hemorrhage. AMTSL has three components:

- Administration of an oxytocic drug to speed effective uterine contractions and separation of placenta;

- Controlled cord traction to facilitate quick placental separation, preventing it from becoming trapped in the cervix, and

- Fundal massage/Cutting of umbilical cord.

The knowledge of the midwives was assessed on all three components. Table 9 shows that overall, 75 respondents mentioned fundal massage/cord cutting. In both Jhelum and Sukkur, all but one midwife reported this step, while only 4 out 14 reported this step in D.G. Khan. Seventy CMWs reported knowledge of administration of oxytocic drugs; 63 mentioned controlled cord traction.

Table 9: Number of community midwives who correctly knew specific steps in active management of third-stage of labor, by district

\begin{tabular}{lrrrrrrr}
\hline Steps & Rawalpindi & Jhelum & Khanewal & D.G. Khan & Dadu & Sukkur & Total \\
\hline $\begin{array}{l}\text { Administration of } \\
\text { oxytocic drugs }\end{array}$ & 11 & 5 & 9 & 9 & 30 & 6 & 70 \\
\hline $\begin{array}{l}\text { Controlled cord traction } \\
\text { Fundal massage/cord }\end{array}$ & 7 & 3 & 9 & 6 & 31 & 7 & 63 \\
\hline $\begin{array}{l}\text { cutting } \\
\text { Don't know }\end{array}$ & 12 & 9 & 9 & 4 & 35 & 6 & 75 \\
\hline Total respondents & 2 & 0 & 2 & 3 & 3 & 0 & 10 \\
\hline Note: Multiple responses possible. & $\mathbf{1 9}$ & $\mathbf{1 0}$ & $\mathbf{1 7}$ & $\mathbf{1 4}$ & $\mathbf{3 9}$ & $\mathbf{7}$ & $\mathbf{1 0 6}$ \\
\hline
\end{tabular}

Note: Multiple responses possible. 
- 36 percent of midwives knew all steps of AMTSL.

- 9 percent of midwives did not know any steps of AMTSL.

- No midwife from Jhelum or D.G. Khan knew all steps of AMTSL.

\section{Complications requiring referral}

Prompt recognition and referral of obstetrical complications plays a key role in reduction of maternal mortality. Midwives should have knowledge of complications that require referral so that patients can be referred in a timely manner to appropriate health facilities.

Figure 9 shows data on the knowledge of midwives about different obstetrical complication requiring referral. The majority of respondents mentioned fits/convulsions, followed closely by malposition of fetus and heavy bleeding before placenta comes out. The other most commonly mentioned by at least half of the midwives were: heavy or constant bleeding after placenta comes out and cessation of labor pains. All other symptoms were mentioned by less than half of the midwives. In Jhelum, the response rate was 100 percent for malposition of fetus and fits/convulsions; in Sukkur 100 percent mentioned early rupture of membrane.

Figure 9: Percentage of community midwives who correctly knew specific obstetrical complications requiring referral

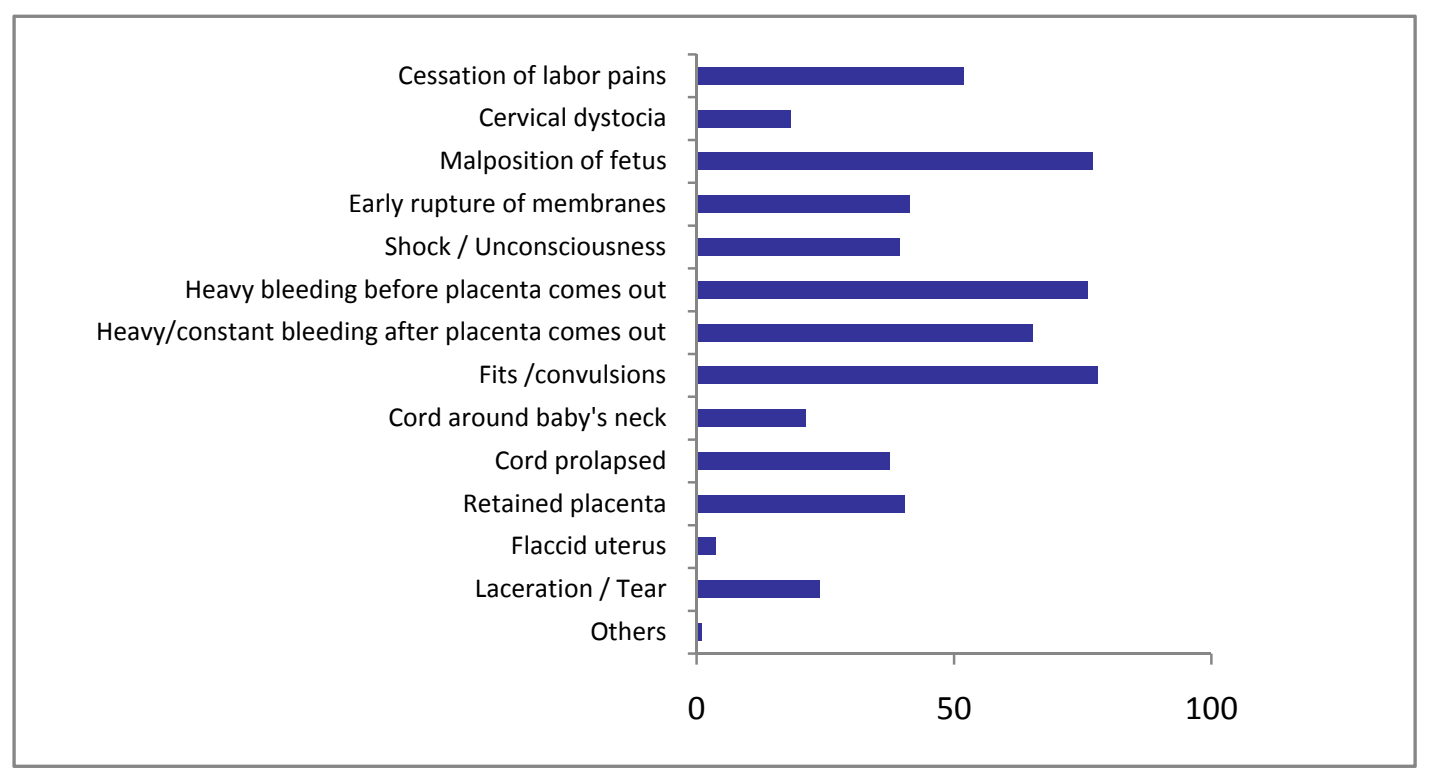


- 27 percent of midwives knew 9 obstetrical complications requiring referral.

- 15 percent of midwives knew 5 obstetrical complications requiring referral

- No midwife knew all obstetrical complications requiring referral.

\section{Danger signs in postpartum period}

The postpartum period is the time immediately after a woman delivers her baby. It lasts approximately 6 weeks. Women can experience a variety of symptoms, but there are some symptoms that are considered to be danger signs. Midwives should have knowledge of these danger signs in order to manage or refer a patient in a timely manner.

Table 10 shows knowledge of midwives on five specific danger signs of the postpartum period. The majority of respondents (99) mentioned excessive vaginal bleeding as a danger sign; this was mentioned by all CMWs from Jhelum and Sukkur. The next most reported danger sign was high fever with or without rigors mentioned by $81 \mathrm{CMWs}$, with a 100 percent response from Sukkur. On the whole, the level of knowledge for other danger signs was low: only 29 respondents mentioned fits or convulsions, 18 mentioned prolapsed uterus, and 15 mentioned unconsciousness.

Table 10: Number of community midwives who spontaneously knew postpartum danger signs correctly, by district

\begin{tabular}{lrrrrrrr}
\hline Danger signs & Rawalpindi & Jhelum & Khanewal & D.G. Khan & Dadu & Sukkur & Total \\
\hline Excessive vaginal bleeding & 18 & 10 & 15 & 11 & 38 & 7 & 99 \\
\hline Fits or convulsions & 2 & 3 & 2 & 6 & 12 & 4 & 29 \\
\hline Unconsciousness & 1 & 0 & 2 & 1 & 10 & 1 & 15 \\
\hline $\begin{array}{l}\text { High fever with or without } \\
\text { rigors }\end{array}$ & 16 & 8 & 13 & 9 & 28 & 7 & 81 \\
\hline $\begin{array}{l}\text { Prolapsed uterus } \\
\text { Total respondents }\end{array}$ & $\mathbf{1 9}$ & $\mathbf{1 0}$ & $\mathbf{1 7}$ & $\mathbf{1 4}$ & $\mathbf{3 9}$ & $\mathbf{7}$ & $\mathbf{1 0 6}$ \\
\hline Note: Multiple responses possible. & & & & 0 & & & \\
\hline
\end{tabular}


- 42 percent of midwives knew 3 or more danger signs of the postpartum period.

- No midwife knew all danger signs of the postpartum period.

- 1 percent of midwives did not know any danger signs of the postpartum period.

\section{Puerperal sepsis}

Puerperal sepsis is any bacterial infection of the female genital tract that appears after delivery. Usually, the sign and symptoms appear 24 hours after birth. For midwives, it is extremely important to be able to treat puerperal sepsis promptly and properly.

Table 11 shows the knowledge of midwives regarding different steps of management of puerperal sepsis. Somewhat over half of the respondents mentioned use of antibiotics (63). Almost half of the respondents (50) mentioned referral for management of patient. On the whole, 42 respondents mentioned management of vital signs; in D.G. Khan and Khanewal none of the respondents mentioned this. IV fluids were mentioned by only 21 respondents; in Jhelum and Khanewal none of the respondents mentioned this. The leastmentioned step was input-output monitoring, stated by a total of only 5 respondents. There were 15 midwives who had no knowledge regarding management of puerperal sepsis.

Table 11: Number of community midwives who correctly knew specific steps in managing puerperal sepsis, by district

\begin{tabular}{lrrrrrrr}
\hline Step & Rawalpindi & Jhelum & Khanewal & D.G. Khan & Dadu & Sukkur & Total \\
\hline $\begin{array}{l}\text { Vital signs (BP, RR, pulse, } \\
\text { temp.) }\end{array}$ & 2 & 4 & 0 & 0 & 29 & 7 & 42 \\
\hline IV fluids & 1 & 0 & 0 & 1 & 17 & 2 & 21 \\
\hline Antibiotics & 10 & 8 & 12 & 5 & 25 & 3 & 63 \\
\hline Input/output monitoring & 2 & 1 & 0 & 0 & 2 & 0 & 5 \\
\hline Referral & 11 & 4 & 8 & 2 & 19 & 6 & 50 \\
\hline Don't know & 2 & 1 & 0 & 9 & 3 & 0 & 15 \\
\hline Total respondents & $\mathbf{1 9}$ & $\mathbf{1 0}$ & $\mathbf{1 7}$ & $\mathbf{1 4}$ & $\mathbf{3 9}$ & $\mathbf{7}$ & $\mathbf{1 0 6}$ \\
\hline
\end{tabular}

- 30 percent of midwives knew three of the steps for managing puerperal sepsis.

- No midwife knew all of the steps for managing puerperal sepsis. 
- 14 percent of midwives did not know any steps for managing of puerperal sepsis.

\subsection{Knowledge: Neonatal Health}

Knowledge of CMWs was assessed on different aspects of neonatal health. For assessing the knowledge of danger signs of newborn, midwives were first asked in general (spontaneous knowledge) and later they were prompted regarding the five most important danger signs. The other issues related to neonatal health for which only spontaneous knowledge was appraised included: management of newborn immediately after delivery, APGAR score, prevention of neonatal tetanus, neonatal complications requiring referral, and immunization.

\section{Danger Signs}

Information related to newborn danger signs that was collected included: baby won't cry/weak cry, difficult breathing, blue skin color, fits, and inability to suckle. Table 12 shows spontaneous knowledge by district regarding danger signs in newborns. Among five danger signs, the majority of respondents mentioned difficult breathing (78) and blue skin color (76). In Jhelum, Khanewal and Sukker, the baby's inability to suckle was either not mentioned as a danger sign or was mentioned by only one midwife.

Table 12: Number of community midwives who spontaneously knew specific danger signs in newborns correctly, by district

\begin{tabular}{lrrrrrrr}
\hline Sign & Rawalpindi & Jhelum & Khanewal & D.G. Khan & Dadu & Sukkur & Total \\
\hline $\begin{array}{l}\text { Baby won't cry/ } \\
\text { weak cry }\end{array}$ & 11 & 5 & 9 & 4 & 26 & 6 & 61 \\
\hline Difficult breathing & 17 & 8 & 10 & 12 & 25 & 6 & 78 \\
\hline Blue skin color & 12 & 8 & 11 & 10 & 30 & 5 & 76 \\
\hline Fits & 2 & 2 & 6 & 3 & 15 & 4 & 32 \\
\hline Unable to suck & 2 & 0 & 1 & 4 & 6 & 1 & 14 \\
\hline Total respondents & $\mathbf{1 9}$ & $\mathbf{1 0}$ & $\mathbf{1 7}$ & $\mathbf{1 4}$ & $\mathbf{3 9}$ & $\mathbf{7}$ & $\mathbf{1 0 6}$ \\
\hline
\end{tabular}

Note: Multiple responses possible.

- 53 percent of midwives knew 3 or more danger signs for newborns.

- No midwife knew all danger signs for newborns.

- 4 percent of midwives did not know any danger signs for newborns. 


\section{Delivery care}

Proper care of the newborn includes a number of actions that a midwife should take immediately after the birth: ensuring warmth of the baby, taking care of the cord, assessing baby's condition using Apgar score, examining the baby, assisting mother to put the baby to the breast, treating the baby's eyes, weighing the baby, completing the records, and ensuring that mother and newborn are comfortable. The first and most important step of ensuring the baby is warm was mentioned by 96 midwives; this was followed by care for the cord (66), assessment of baby's condition by APGAR score (61), and assisting the women to put the baby to the breast (60) (Table 13). Less than half of the midwives mentioned weighing the baby or eye treatment. Slightly more than onethird of midwives responded about detailed examination of the newborn and one-third mentioned record completion. It is noteworthy that the response rate was 100 percent for the first three steps in Sukkur. In D.G. Khan, none of the midwives had knowledge about eye treatment, weighing the baby, completion of records or ensuring that mother and newborn are comfortable. Completing records was also not mentioned in Khanewal or Jhelum, while ensuring that mother and newborn are comfortable was not mentioned anywhere but in Dadu.

Table 13: Number of community midwives who correctly knew specific steps in newborn care, by district

\begin{tabular}{|c|c|c|c|c|c|c|c|}
\hline Steps & Rawalpindi & Jhelum & Khanewal & D.G. Khan & Dadu & Sukkur & Total \\
\hline Ensure warmth of baby & 17 & 8 & 15 & 11 & 38 & 7 & 96 \\
\hline Care for cord & 13 & 9 & 5 & 3 & 29 & 7 & 66 \\
\hline Assess baby (Apgar score) & 11 & 6 & 7 & 2 & 28 & 7 & 61 \\
\hline $\begin{array}{l}\text { Assist women in putting } \\
\text { baby to breast }\end{array}$ & 14 & 5 & 3 & 5 & 29 & 4 & 60 \\
\hline Eye treatment & 4 & 6 & 2 & 0 & 30 & 3 & 45 \\
\hline Weigh baby & 1 & 3 & 4 & 0 & 36 & 6 & 50 \\
\hline $\begin{array}{l}\text { Detailed examination of } \\
\text { newborn }\end{array}$ & 9 & 8 & 2 & 2 & 16 & 1 & 38 \\
\hline Complete the records & 1 & 0 & 0 & 0 & 28 & 6 & 35 \\
\hline $\begin{array}{l}\text { Ensure mother and } \\
\text { newborn are comfortable }\end{array}$ & 0 & 0 & 0 & 0 & 8 & 0 & 8 \\
\hline Don't know & 0 & 0 & 0 & 0 & 1 & 0 & 1 \\
\hline Total respondents & 19 & 10 & 17 & 14 & 39 & 7 & 106 \\
\hline
\end{tabular}

Note: Multiple responses possible. 
- 11 percent of midwives knew 5 steps in newborn care.

- 7 percent of midwives knew 8 steps in newborn care.

- No midwife knew all of the steps in newborn care.

- 1 percent of midwives did not know any steps in newborn care.

\section{Apgar score}

The Apgar score is a useful tool for assessing the newborn's condition. It uses the five vital signs at birth to give a score. Apgar score is a mnemonic for:
A Appearance (i.e., color)
$P$ Pulse (i.e., heart rate)
$\mathrm{G}$ Grimace (i.e., response to stimuli)
A Activity (i.e., tone)
$\mathrm{R}$ Respiration

It is the responsibility of the midwife to assess a newborn's condition at 1 minute and 5 minutes after birth using the Apgar score. To do this properly, the midwife should have knowledge of all components of the score. Table 14 shows the knowledge of CMWs on all components of an Apgar score. The majority of midwives had knowledge about appearance (94), respiration (86) and pulse (85). Two-thirds mentioned being active and having grimace. The response rate was 100 percent for appearance, pulse, active and respiration in Sukkur and for first three components in Jhelum. There were 8 midwives who had no knowledge of the Apgar score; among these, 4 were from D.G. Khan.

Table 14: Number of community midwives who correctly knew components of Apgar score, by district

\begin{tabular}{lrrrrrrr}
\hline Apgar components & Rawalpindi & Jhelum & Khanewal & D.G. Khan & Dadu & Sukkur & Total \\
\hline Appearance (i.e., color) & 17 & 10 & 15 & 8 & 36 & 7 & 94 \\
\hline Pulse (i.e., heart rate) & 16 & 10 & 9 & 6 & 36 & 7 & 85 \\
\hline $\begin{array}{l}\text { Grimace (response to } \\
\text { stimuli) }\end{array}$ & 15 & 10 & 6 & 1 & 31 & 6 & 69 \\
\hline Active (i.e., tone) & 12 & 6 & 9 & 2 & 34 & 7 & 70 \\
\hline Respiration & 16 & 8 & 12 & 8 & 35 & 7 & 86 \\
\hline Don't know & 0 & 0 & 2 & 4 & 2 & 0 & 8 \\
\hline Total respondents & $\mathbf{1 9}$ & $\mathbf{1 0}$ & $\mathbf{1 7}$ & $\mathbf{1 4}$ & $\mathbf{3 9}$ & $\mathbf{7}$ & $\mathbf{1 0 6}$ \\
\hline
\end{tabular}

Note: Multiple responses possible. 
- 49 percent of midwives knew all of the components of an Apgar score.

- 8 percent of midwives did not know any component of an Apgar score.

- No midwives in D.G. Khan knew all components of an Apgar score.

\section{Neonatal tetanus}

As far as steps to prevent neonatal tetanus, the majority of midwives (80) had knowledge that all pregnant women should be immunized (Table 15). The response rate was 100 percent in Dadu and Sukkur. About half of the midwives (54) knew one of the steps was proper care of the cord and less than half (47 CMWs) mentioned clean delivery practices. None of the respondents from Khanewal or D.G. Khan had knowledge about clean delivery practices as an important step to prevent neonatal tetanus, while proper care of the cord was not mentioned in Khanewal at all and by only one midwife in D.G. Khan.

Table 15: Number of community midwives who correctly knew steps in prevention of neonatal tetanus, by district

\begin{tabular}{lcrrrrrr}
\hline Step & Rawalpindi & Jhelum & Khanewal & D.G. Khan & Dadu & Sukkur & Total \\
\hline $\begin{array}{l}\text { Proper immunization } \\
\text { of pregnant women } \\
\text { before delivery }\end{array}$ & 9 & 2 & 13 & 10 & 39 & 7 & 80 \\
\hline $\begin{array}{l}\text { Clean delivery } \\
\text { practices }\end{array}$ & 9 & 7 & 0 & 0 & 28 & 3 & 47 \\
\hline Proper care of cord & 9 & 8 & 0 & 1 & 30 & 6 & 54 \\
\hline Don't know & 4 & 1 & 4 & 3 & 0 & 0 & 12 \\
\hline $\begin{array}{l}\text { Number of } \\
\text { respondents }\end{array}$ & $\mathbf{1 9}$ & $\mathbf{1 0}$ & $\mathbf{1 7}$ & $\mathbf{1 4}$ & $\mathbf{3 9}$ & $\mathbf{7}$ & $\mathbf{1 0 6}$ \\
\hline
\end{tabular}

Note: Multiple responses possible.

- 29 percent of midwives knew all of the steps to prevent neonatal tetanus.

- 11 percent of midwives did not know any steps to prevent neonatal tetanus.

- No midwife in Khanewal or D.G. Khan knew all 3 steps to prevent neonatal tetanus.

\section{Complications requiring referral}

There are several newborn complications that, if they occur, require referral. Therefore, midwives should be able to recognize such complications for timely referral to appropriate health facilities. Figure 10 shows the knowledge of midwives on different neonatal complications requiring referral. The most common neonatal complication 
mentioned by midwives was very pale or blue color of baby after first few minutes of birth; 82 respondents mentioned this complication. The next highest response was regarding labored breathing of baby (76), followed by: baby does not breath at all (71). Less than one-third of the midwives mentioned baby has no heart beat and heart beat is less than 80 beats per minute.

Figure 10: Percentage of community midwives who correctly knew specific neonatal complications requiring referral

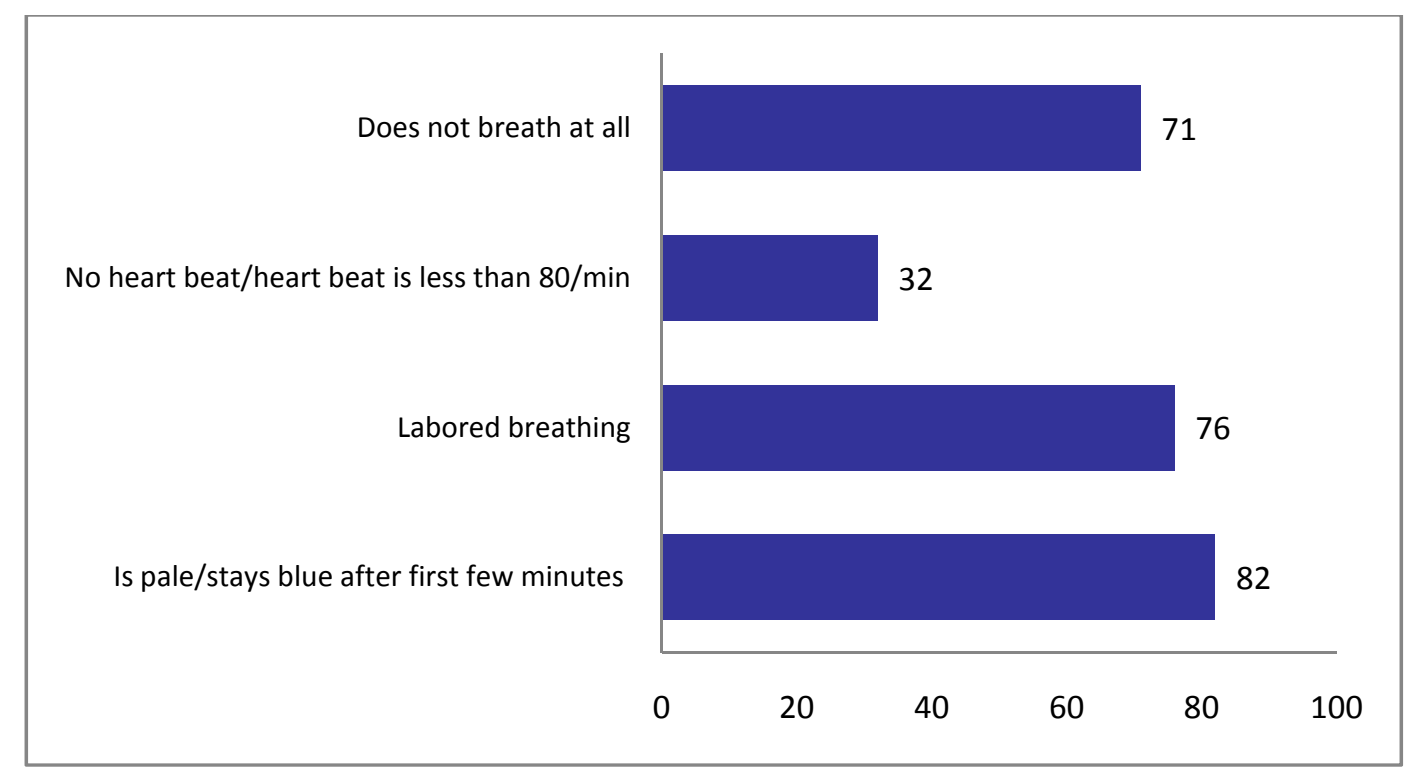

- 14 percent of midwives knew all 4 neonatal complications requiring referral.

- 2 percent of midwives did not know any neonatal complication requiring referral.

- No midwife from Rawalpindi, Khanewal, D.G. Khan or Sukkur knew all 4 neonatal complications requiring referral.

\subsection{Placement of Trained Midwives}

After completing their training (course work, practical training in the hospital and community training) and successfully passing their examinations, all of the midwives were introduced in the community. They were subsequently facilitated in establishing their midwifery homes by the PAIMAN project, which provided them equipment so they could establish their $\mathrm{MWH}$ and begin providing services to their communities. 


\section{Midwifery homes}

At the time of interview, 59 out of 106 CMWs (56 percent) had started their work in the community. This work ranged from introduction in the community to visiting clients. PAIMAN encouraged and helped these midwives to establish a midwifery home (MWH). It was recommended that a MWH would consist of at least one and preferably two rooms and be equipped with essential items to be provided by PAIMAN. It was recommended that one room would be used as a labor room and the other one as a waiting area for other clients or attendants. All but 4 of the midwives who had started their work by the time of the interview had established MWHs. Table 16 presents details regarding the size of the MWHs established.

Table 16: Number of community midwives who had established a midwifery home, by number of rooms, by district

\begin{tabular}{lrrrrrrr}
\hline Number of rooms & Rawalpindi & Jhelum & Khanewal & D.G. Khan & Dadu & Sukkur & Total \\
\hline 1 & 12 & 6 & 14 & 8 & 4 & 4 & 48 \\
\hline 2 & 2 & 0 & 2 & 1 & 1 & 0 & 6 \\
\hline 3 & 0 & 0 & 1 & 0 & 0 & 0 & 1 \\
\hline $\begin{array}{l}\text { Number of } \\
\text { respondents }\end{array}$ & $\mathbf{1 4}$ & $\mathbf{6}$ & $\mathbf{1 7}$ & $\mathbf{9}$ & $\mathbf{5}$ & $\mathbf{4}$ & $\mathbf{5 5}$ \\
\hline
\end{tabular}

\section{Facilities}

Ample amount of clean water and electricity are the two utilities that are very important in the management of obstetrical and newborn cases. All CMWs had electricity in their MWHs, while 39 out of $55 \mathrm{MWHs}$ had a water supply. A running water supply was available in 8 out of 17 MWHs in Khanewal, 4 out of 9 in D.G. Khan, 4 out of 5 in Dadu, and 3 out of 4 in Sukkur.

\section{Referral links and transport}

One of the important messages given to the CMWs during training is timely referral for any obstetrical and newborn complication that they cannot manage themselves. The value of a referral system increases when an appropriate link exists between a community health care provider and a referral health facility. 
A remarkably high number of midwives (100) responded that they had established linkages with some type of referral health facility. When analyzed by district, all midwives from D.G. Khan, Dadu and Sukkur, and almost all from the rest of the districts, stated that they had developed referral linkages.

When further asked about the type of health facility with which linkages existed, they named a variety of facilities (Table 17). This was a multiple response variable. District Headquarters Hospital (DHQH) was mentioned by 49 midwives (50 percent), followed by Tehsil Headquarters Hospital (THQH). Only one midwife from Sindh province (Dadu and Sukkur districts) stated BHU as the referral health facility, while none of them named RHC. Links to BHUs were reported by 8 out of 17 CMWs from Rawalpindi and 4 out of 14 from D.G. Khan, while a higher number from D.G. Khan (6/14) and fewer from Rawalpindi (3/17) reported RHC as a referral health facility. In Khanewal, apart from $\mathrm{THQH}$, the response for other facilities as a referral facility was low.

Even though many midwives had begun to make referral links with health facilities at the time of the interviews, and the CMWs had not started their work to an extent that they were referring complicated cases, it was noted that they did know the importance of such referral linkages.

Table 17: Number of community midwives who had made specific types of referral links, by district

\begin{tabular}{lrrrrrrr}
\hline Type of link & Rawalpindi & Jhelum & Khanewal & D.G. Khan & Dadu & Sukkur & Total \\
\hline $\begin{array}{l}\text { Formal liaison with } \\
\text { BHU }\end{array}$ & 8 & 3 & 2 & 4 & 1 & 0 & 18 \\
\hline $\begin{array}{l}\text { Formal liaison with } \\
\text { RHC }\end{array}$ & 3 & 3 & 2 & 6 & 0 & 0 & 14 \\
\hline $\begin{array}{l}\text { Formal liaison with } \\
\text { THQ }\end{array}$ & 7 & 3 & 7 & 3 & 11 & 2 & 33 \\
\hline $\begin{array}{l}\text { Formal liaison with } \\
\text { DHQ }\end{array}$ & 2 & 3 & 2 & 9 & 28 & 5 & 49 \\
\hline $\begin{array}{l}\text { Other } \\
\text { Number of } \\
\text { respondents }\end{array}$ & 2 & 0 & 1 & 0 & 0 & 0 & 3 \\
\hline
\end{tabular}

Note: Multiple responses were possible.

Among the midwives who reported the existence of referral linkages, more than twothirds also reported about the availability of transport (Figure 11). Across the districts, comparatively more midwives from Rawalpindi and Dadu knew about such facilities than 
those from Khanewal and Sukkur. All midwives from Jhelum but less than one-third from D.G. Khan had knowledge of an emergency transport facility in their community.

Figure 11: Percentage distribution of community midwives who knew about available transport for emergency referrals, by district

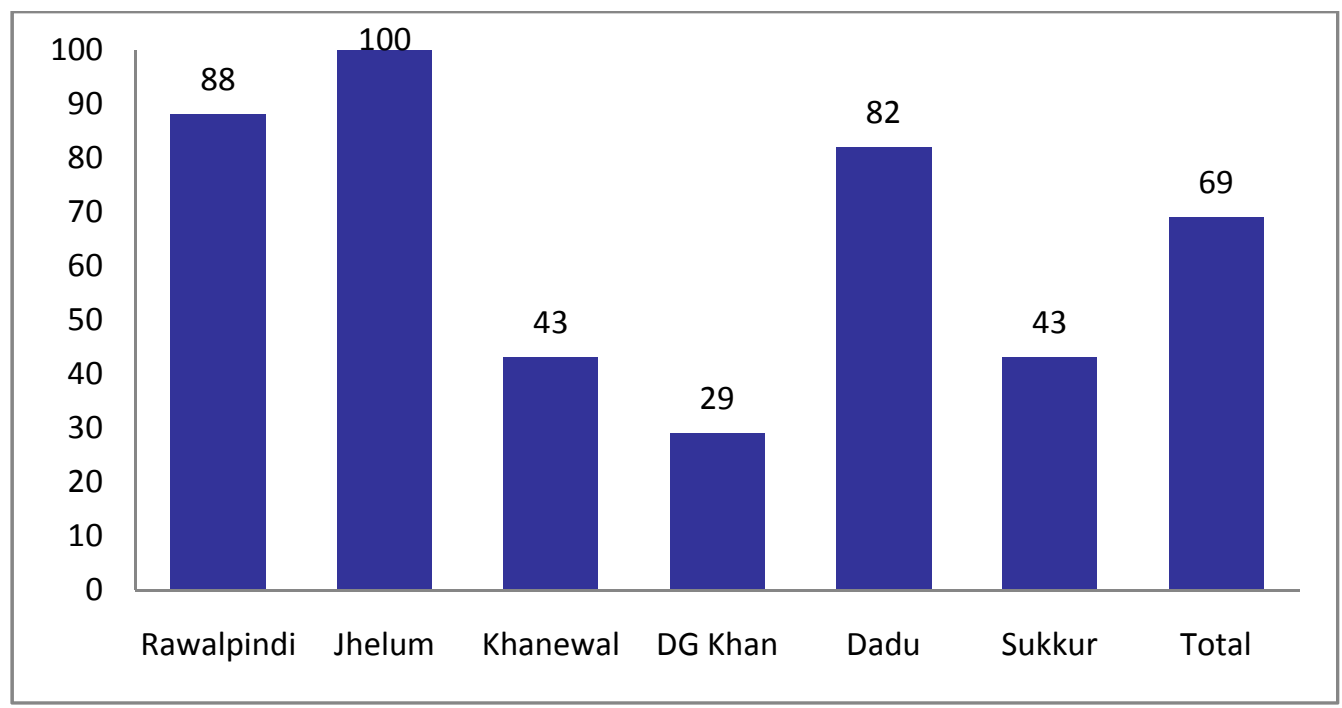

These midwives also had information about the different types of transport facilities available and used in their communities. Table 18 shows that there was a higher response (52 out of $71 \mathrm{CMWs)} \mathrm{reporting} \mathrm{family} \mathrm{arrangements} \mathrm{as} \mathrm{compared} \mathrm{to} \mathrm{arrangement} \mathrm{by} \mathrm{the}$ community (11 out of 71 CMWs) and public-sector ambulance (4 out of 71 CMWs). In all of the districts except Khanewal and D.G. Khan, a majority of the midwives reported transport arrangements by the family. More midwives from Khanewal and D.G. Khan reported community arrangements over family.

Table 18: Number of community midwives who reported specific transport arrangements for referrals, by district

\begin{tabular}{lrrrrrrr}
\hline Arrangement & Rawalpindi & Jhelum & Khanewal & D.G. Khan & Dadu & Sukkur & Total \\
\hline Public sector ambulance & 1 & 1 & 1 & 0 & 1 & 0 & 4 \\
\hline $\begin{array}{l}\text { Arrangement by } \\
\text { community }\end{array}$ & 0 & 0 & 3 & 3 & 5 & 0 & 11 \\
\hline Arrangement by family & 14 & 8 & 0 & 0 & 27 & 3 & 52 \\
\hline Other & 0 & 0 & 2 & 2 & 0 & 0 & 4 \\
\hline Number of respondents & 15 & 9 & 6 & 5 & 33 & 3 & 71 \\
\hline
\end{tabular}




\section{Existing providers}

Overall, 8 midwives reported that there was no LHW in their community; 6 of these CMWs were from Dadu and 1 each from Jhelum and D.G. Khan. Five CMWs from D.G. Khan and 11 from Khanewal reported that there were six or more LHWs working in their communities. Three CMWs in Rawalpindi, 3 in Jhelum, 4 in Dadu and 2 in Sukkur reported 6 or more LHWs were working in their catchment area.

When asked about the presence of dais in their communities, 19 midwives stated that there was no dai present in their community. Across districts, 4 midwives from Rawalpindi, 3 from Jhelum, 1 from D.G. Khan, 9 from Dadu and 2 from Sukkur did not have a single dai who was working in their communities. Like LHWs, the number of dais also fluctuated across districts: 2 midwives from Rawalpindi, 9 from Khanewal, 4 from D.G. Khan and 1 from Dadu reported that 6 or more dais were working in their communities.

Estimates of the mean numbers of LHWs and dais present in the districts were made. Figure 12 shows that D.G. Khan was the district where both LHWs and dais were present in relatively higher number (mean number of $\mathrm{LHWS}=8$; mean number of dais $=3$ ), followed by Khanewal. Rawalpindi and Dadu were the districts where the mean number of LHWs was the lowest (mean number $=3$ ). The mean number of dais was the lowest in Jhelum, Sukkur and Dadu.

Figure 12: Mean number of LHWs and dais in the community midwives' catchment areas, by district

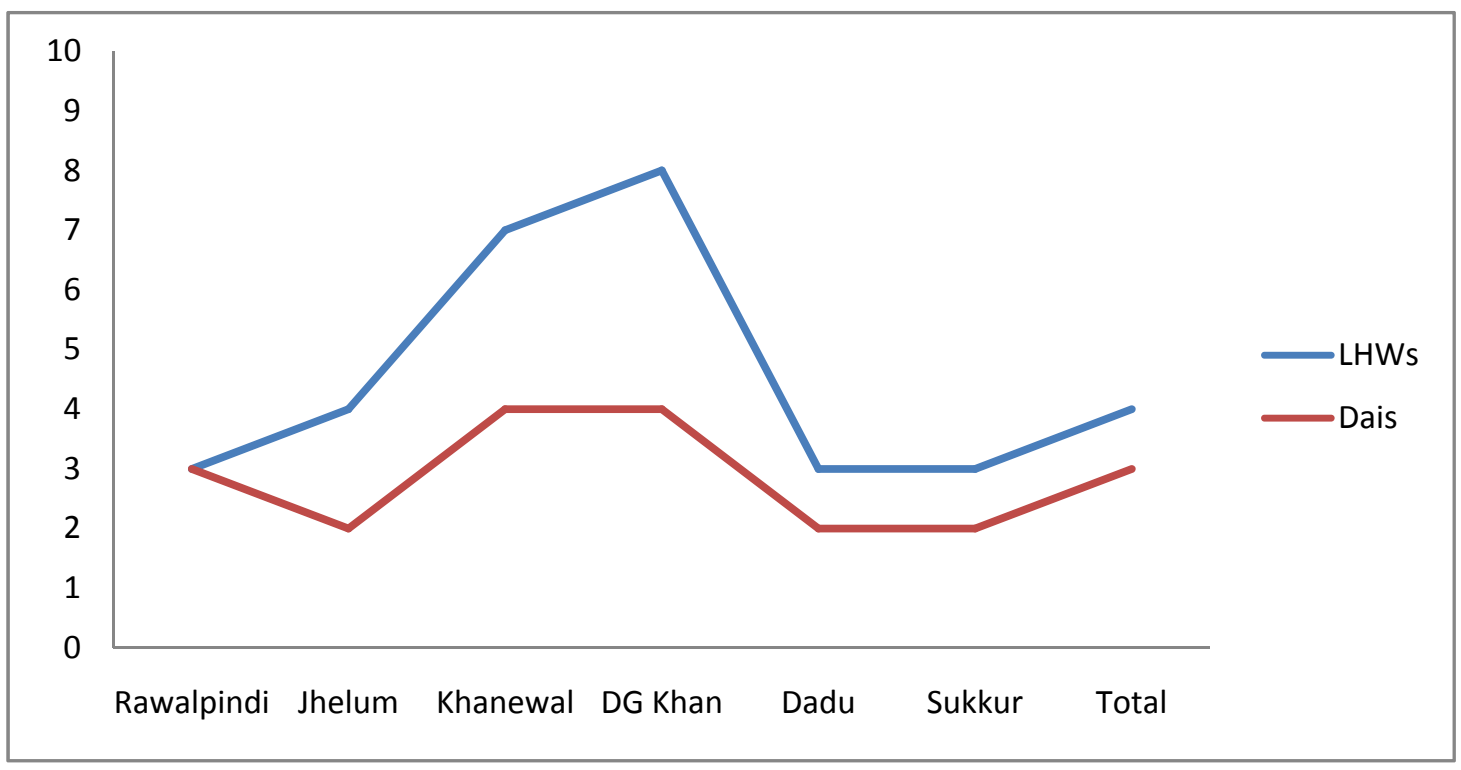


As the existing community health care providers (LHWs and dais) and the CMWs will be working in the same areas, a CMW will have to develop a good working relationship with these providers. In this context, 96 midwives (91 percent) reported having been introduced to LHWs and 66 mentioned that they had developed or were developing a working relationship with them (Figure 13). On the other hand, slightly fewer numbers of CMWs (87) had been introduced to dais, while 43 had developed or were in the process of developing a working relationship.

Figure 13: Percentage of community midwives, by nature of contact with LHWs and dais

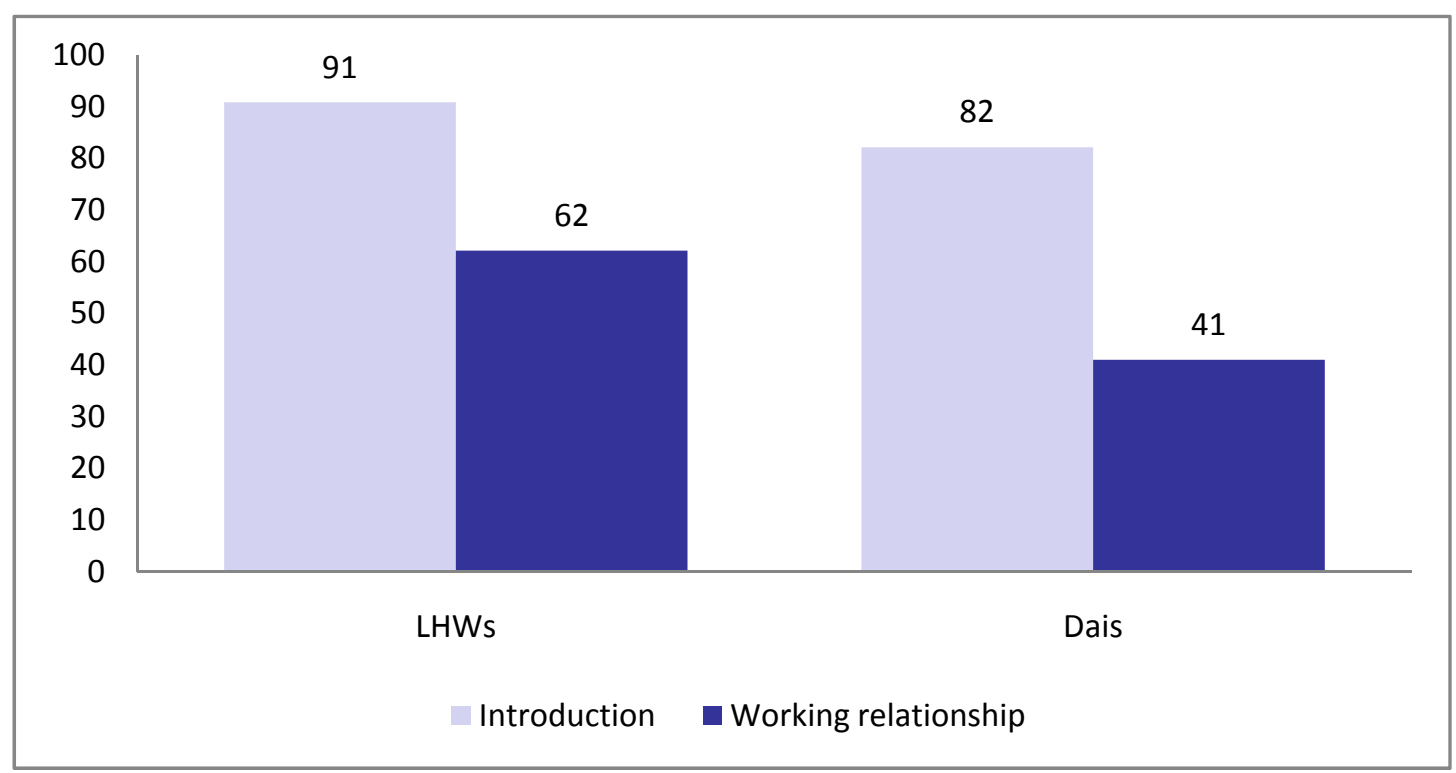

Responding to a question regarding the various types of roles an LHW or dai could play in maternal and neonatal health, the midwives suggested a variety of roles/tasks (Figure 14). 
Figure 14: Percentage of community midwives stating specific roles for LHWs and dais

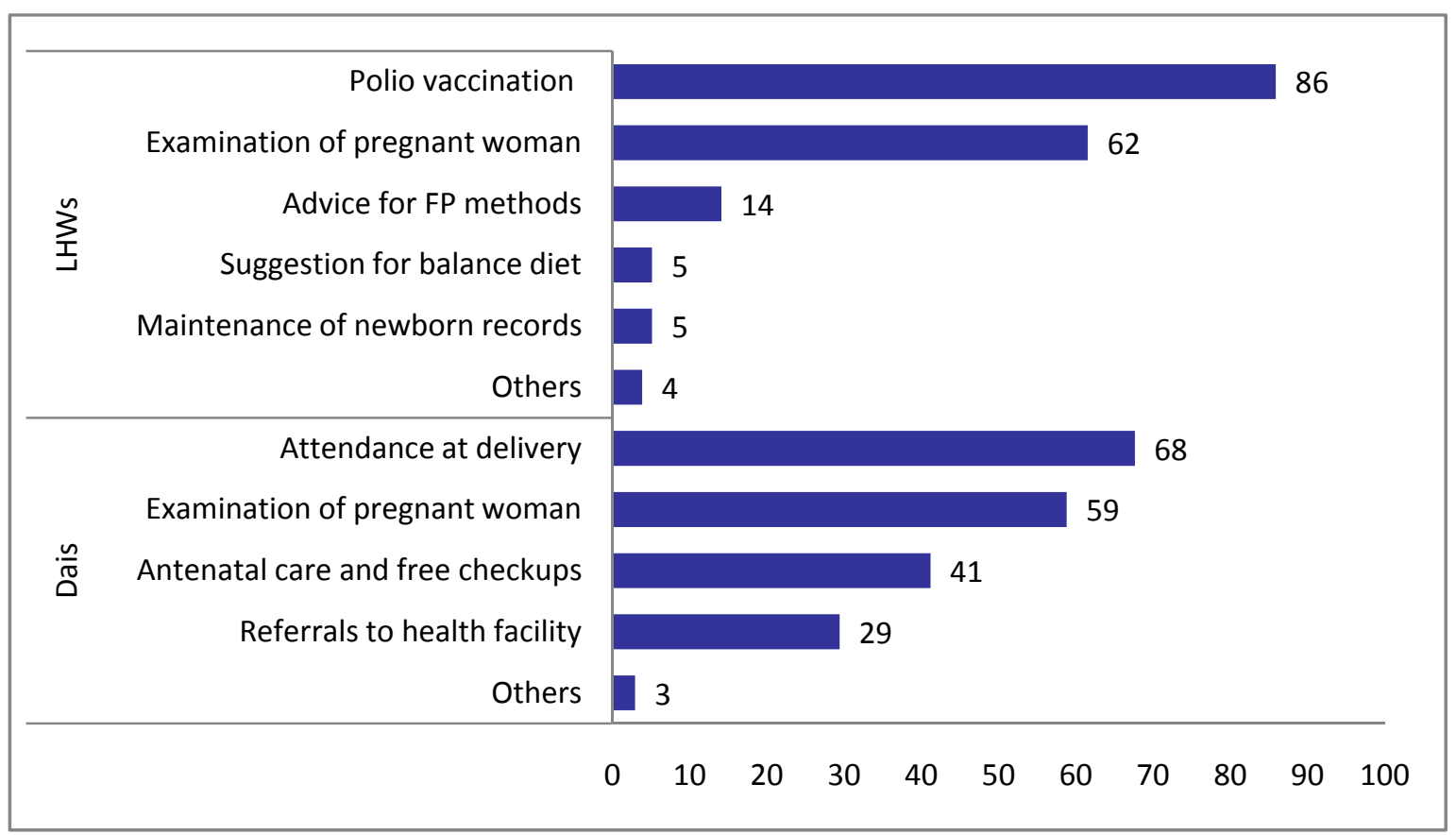

Note: multiple responses were possible.

\section{Improving placements}

In response to a question, CMWs provided some suggestions that could help in improving their placement in the communities (Figure 15). Door-to-door visits were suggested most frequently by the midwives, followed by free antenatal check-ups and friendly attitude. The other suggestions were meeting with leaders in the community and coordination with the health care providers. 
Figure 15: Percentage of CMWs who made specific suggestions for improving their community placements

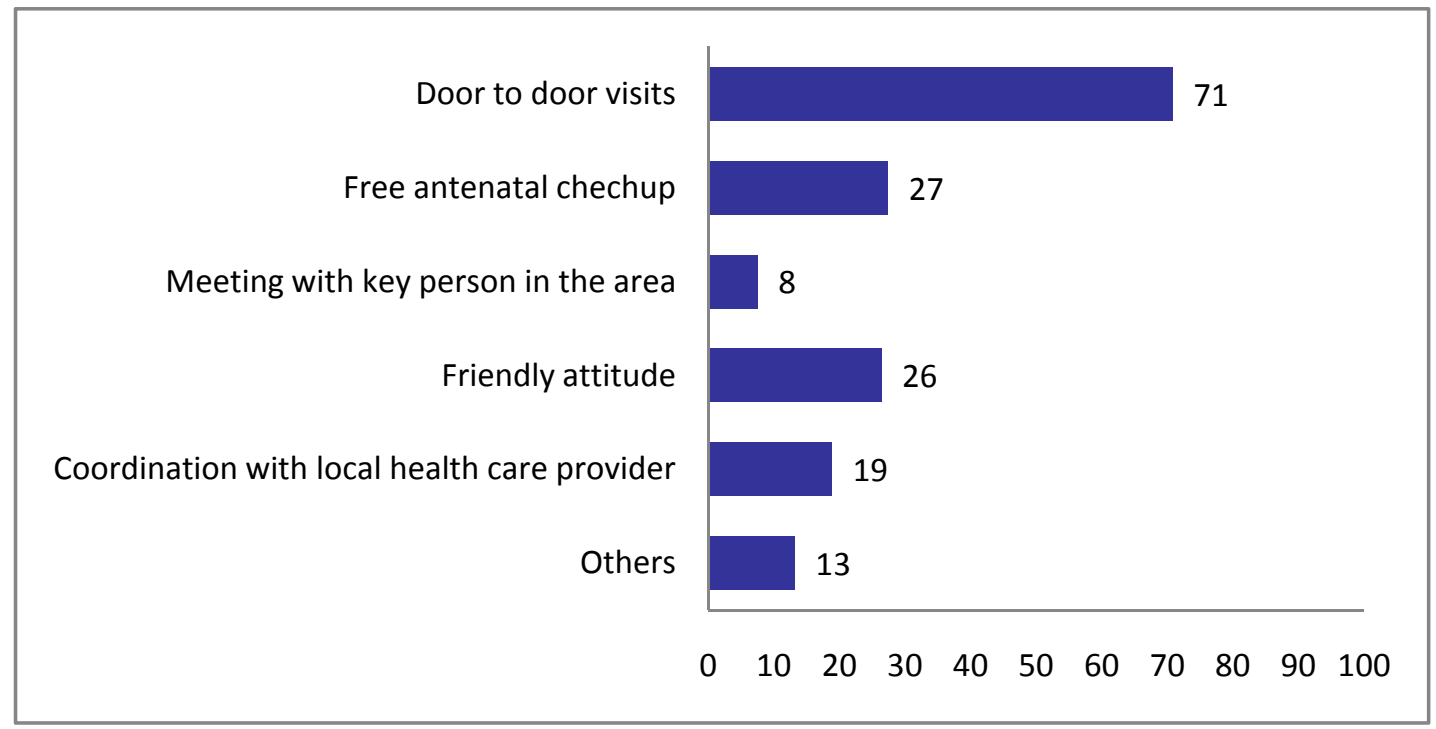

\section{Expectations of provider responses}

In most of the communities where these midwives will be placed for their future work, lady health workers and traditional birth attendants are already serving the women. The midwives provided their opinion about the response of the community health care providers already working in the area on the placement of CMWs. They were more optimistic about working with LHWs than with TBAs: $90 \mathrm{CMWs}$ reported that they expected cooperation from LHWs, while 56 said that they expected cooperation from TBAs.

The midwives were of the opinion that they will be facilitated and receive cooperation from the existing care providers in the community, the LHWs and dais, due to the development of good relationships with them and also because of the better technical skills of the midwives (Figure 16). More midwives (83/ 106; 78 percent) related good relationship as a mode of getting cooperation from LHWs as compared to dais (65/106; 61 percent). On the other hands, reporting good skills as a mode of cooperation was reported more for dais (77/106; 73 percent) than LHWs (66/106; 62 percent). 
Figure 16: Percentage of community midwives who stated specific modes of cooperation for existing health care providers

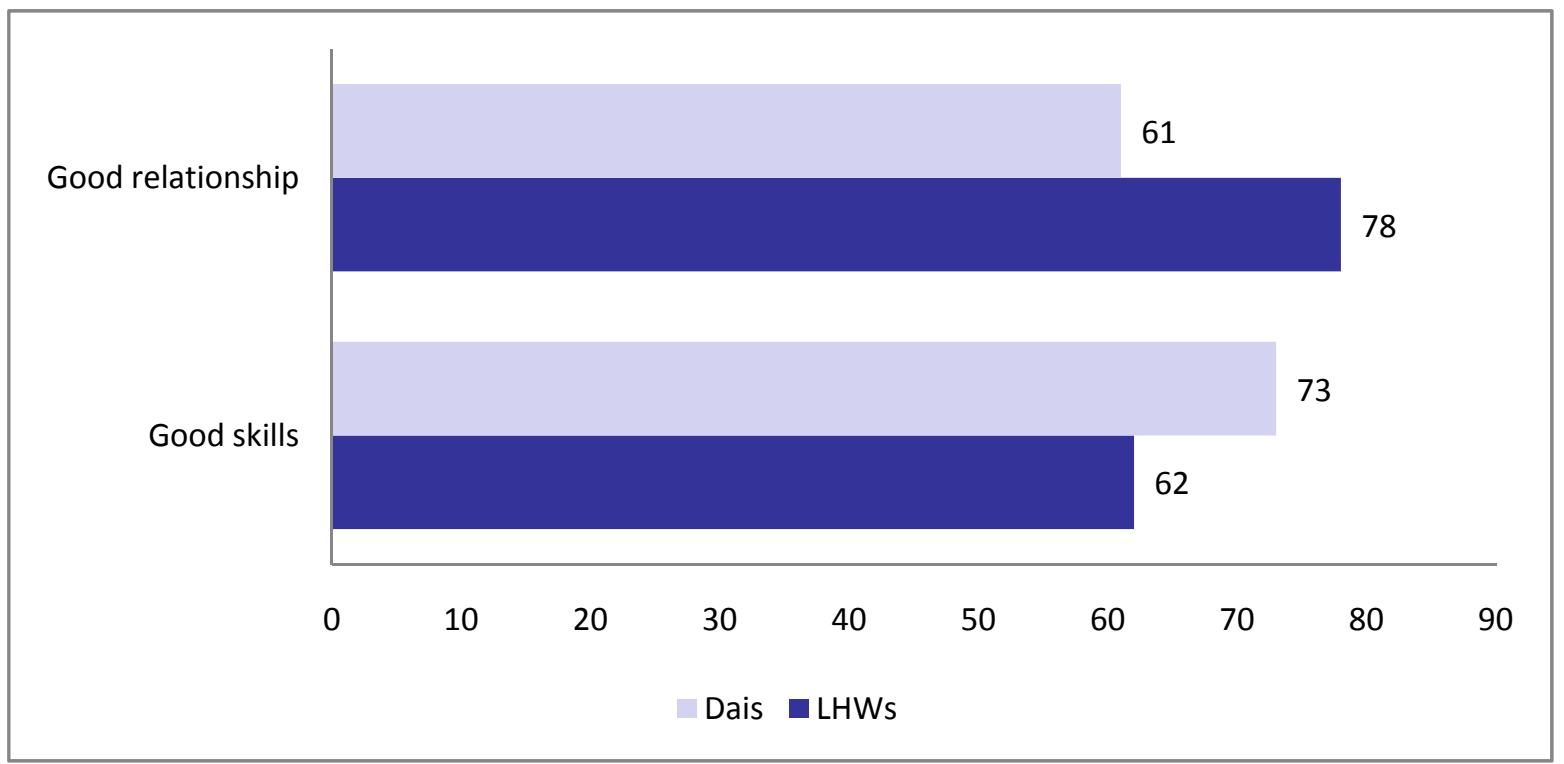

Similarly, midwives also provided information on the potential factors that might lead to lack of cooperation from the LHWs and dais (Figure 17). In comparison with good relationship and good skills, the negative aspect was poor relationship and professional jealousy. Again, poor relationship was cited more for LHWs (60/106; 57 percent) as compared to dais (30/106; 28 percent). More CMWs (74/106; 70 percent) stated professional jealousy as the reason for not receiving appropriate cooperation from dais as compared to LHWs (68/106; 64 percent).

Figure 17: Percentage of community midwives who described specific potential factors for lack of cooperation from existing health care providers

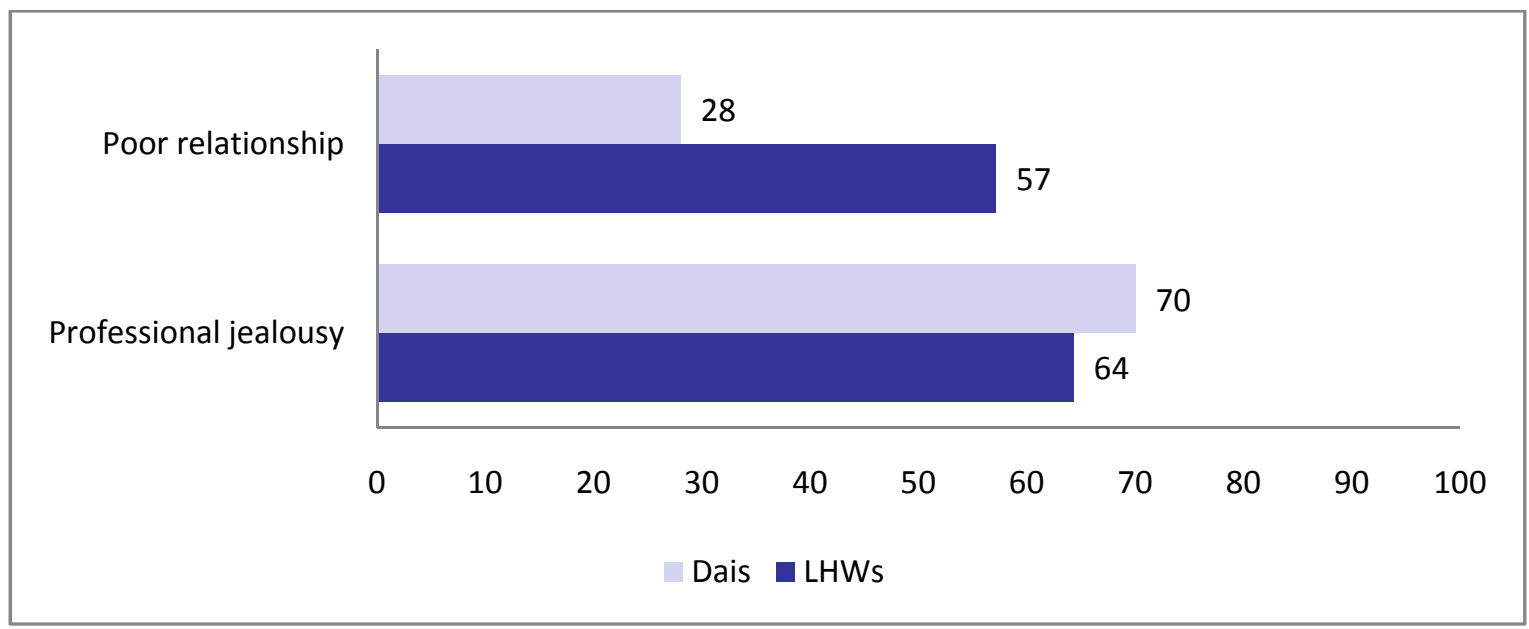




\section{Expectations of community response}

The midwives were asked about their attitude toward women residing in the community -

- how community women would respond to their placement. All midwives unanimously replied, except one from D.G. Khan, that they would be accepted by the community women. The one from D.G. Khan reported that they would not be accepted by the community women as they were a new provider. The reasons cited by the other midwives for their optimism about being received well by the community women were the good skills the CMWs possessed (93), good relationship (64) and easy accessibility (49) (Table 19).

Table 19: Number of community midwives who stated specific reasons for their acceptance by community women, by district

\begin{tabular}{lrrrrrrr}
\hline Reason & Rawalpindi & Jhelum & Khanewal & D.G. Khan & Dadu & Sukkur & Total \\
\hline Good skills & 14 & 10 & 13 & 10 & 39 & 7 & 93 \\
\hline Good relationships & 12 & 6 & 3 & 3 & 35 & 5 & 64 \\
\hline $\begin{array}{l}\text { Easy access and } \\
\text { availability }\end{array}$ & 7 & 0 & 5 & 5 & 27 & 5 & 49 \\
\hline 24-hour availability & 3 & 6 & 0 & 1 & 15 & 2 & 27 \\
\hline Low cost & 5 & 2 & 0 & 1 & 0 & 2 & 10 \\
\hline $\begin{array}{l}\text { Number of } \\
\text { respondents }\end{array}$ & $\mathbf{1 9}$ & $\mathbf{1 0}$ & $\mathbf{1 7}$ & $\mathbf{1 4}$ & $\mathbf{3 9}$ & $\mathbf{7}$ & $\mathbf{1 0 6}$ \\
\hline
\end{tabular}

Note: Multiple responses were possible.

In Table 20, the suggestions that CMWs made about improving their acceptance in their communities are provided. These are similar to those for why they thought they would be well received.

Table 20: Number of community midwives who gave specific suggestions for increasing acceptability in the community, by district

\begin{tabular}{lrrrrrrr}
\hline Suggestions & Rawalpindi & Jhelum & Khanewal & D.G. Khan & Dadu & Sukkur & Total \\
\hline $\begin{array}{l}\text { By good interpersonal } \\
\text { communication skills }\end{array}$ & 14 & 7 & 12 & 8 & 39 & 7 & 87 \\
\hline $\begin{array}{l}\text { By providing good quality } \\
\text { services }\end{array}$ & 10 & 7 & 1 & 5 & 38 & 7 & 68 \\
\hline $\begin{array}{l}\text { By providing care at door } \\
\text { step }\end{array}$ & 13 & 9 & 7 & 3 & 37 & 6 & 75 \\
\hline Number of respondents & 19 & 10 & 17 & 14 & 39 & 7 & 106 \\
\hline
\end{tabular}




\subsection{Skills Assessment}

During the 18-month training period, midwives learned and performed various practical tasks that are carried out at different phases in the examination of a pregnant woman and a newborn. All midwives were assessed as to their performance on some key tasks after the completion of their interviews. A trained lady health visitor (LHV) who conducted the interviews also assessed the skills of the CMWs. A Zoe model was used for the practical demonstration of specific skills, such as: examination of abdomen in a pregnant woman, performing various steps of delivery of a newborn and examination of placenta and umbilical cord. Skill assessment was based on correctly performing an examination following all steps for performing the task. Here, only the numbers performing the tasks correctly are shown in the tables and figures, though the number who performed incorrectly or not performed at all is excluded.

The midwives were assessed for the following skills: examination for anemia, examination for edema, abdominal examination, washing hands, using a clean delivery kit (CDK), performing delivery, cleaning newborn, and checking the cord and placenta after delivery.

\section{Anemia}

On physical examination, anemia (reduced quantity of hemoglobin, which indirectly suggests deficiency of blood) is assessed qualitatively as this is a subjective assessment. Usually, anemia is assessed by the color of the palms of the hands, or color of the nails or color of the sclera in the eyes. A pink color of the former two and red color of the latter is a sign of the absence of anemia (or presence of a sufficient quantity of blood).

All midwives performed assessment of anemia through the examination of eyes, and all except 3 performed it correctly (Table 21). The CMWs across all districts, except Rawalpindi and D.G. Khan, performed this particular task correctly. Slightly fewer (97/106) midwives attempted to assess anemia through nails; out of these, $90 \mathrm{CMWs}$ were able to do it correctly. Assessment of anemia through palms was the least attempted method: less than half ( $37 \mathrm{CMWs} ; 35$ percent) could perform this task correctly. 
Table 21: Number of community midwives who correctly assessed anemia through specific modes, by district

\begin{tabular}{lrrrrrrr}
\hline Mode & Rawalpindi & Jhelum & Khanewal & D.G. Khan & Dadu & Sukkur & Total \\
\hline Eyes & 17 & 10 & 17 & 13 & 39 & 7 & 103 \\
\hline Nails & 17 & 9 & 14 & 8 & 35 & 7 & 90 \\
\hline Palms & 7 & 3 & 5 & 4 & 12 & 6 & 37 \\
\hline $\begin{array}{l}\text { Number of } \\
\text { respondents }\end{array}$ & 19 & 10 & $\mathbf{1 7}$ & $\mathbf{1 4}$ & $\mathbf{3 9}$ & $\mathbf{7}$ & $\mathbf{1 0 6}$ \\
\hline
\end{tabular}

As any of these signs can be used for anemia assessment, a midwife who performed all or at least one test for anemia assessment was awarded a score for correct performance of the examination. All midwives except one from D.G. Khan could assess anemia correctly by at least one of these three methods.

\section{Swelling of feet and hands}

Swelling of feet during pregnancy is usually taken as normal if it reduces or vanishes after taking rest by lying down or sleeping. It becomes alarming when there is no reduction of the swelling of feet, hands and face. CMWs are taught to correctly perform an assessment of the swelling of feet and hands.

Three-quarters of the midwives (81) performed this assessment correctly. Among the districts, midwives from Rawalpindi (18/19), Sukkur (6/7) performed extraordinarily well, followed by Jhelum (8/10), Khanewal (15/17) and Dadu (32/39). Midwives from D.G. Khan did not perform well: only 2 out of 14 did the task correctly.

\section{Abdomen}

One of the most frequent examinations during pregnancy is the examination of the abdomen. This examination provides information regarding various aspect of gestation; it is conducted to assess the size of the uterus, position of the fetus and fetal heart rate. Size of the uterus is helpful in monitoring the growth of the fetus corresponding to the duration of the pregnancy; it also assesses the presence of an adequate amount of fluid in the sac. Assessing the position of the fetus allows the health care provider to attempt to correct the position of the fetus, if necessary and if possible. Fetal heart rate gives an idea about the vitality and health status of the fetus. 
Half of the midwives (53) completed the examination of the abdomen for assessing the size of the uterus correctly (Table 22). In Khanewal, Dadu and Sukkur comparatively more midwives could perform the skill correctly. The performance of midwives from Rawalpindi, Jhelum and D.G. Khan was not satisfactory.

About two-thirds of the midwives (70) completed the task of assessing fetal position correctly; (Table 22). Performance of midwives from Rawalpindi and Jhelum was remarkable as 16 out of 19 and 9 out of 10 respectively performed the task correctly. CMWs from the rest of the districts also performed well (Khanewal - 13/17; Dadu - 26/39; Sukkur - 4/7), with the exception of D.G. Khan, where only 2 CMWs could assess the fetal position applying the correct methods.

Successful performance of assessing the fetal heart rate was slightly lower than that of fetal position: 66 midwives performed the task correctly (Table 22). The performance of CMWs from Jhelum and Dadu was good: 8 out of 10 CMWs in Jhelum and 31 out of 39 in Dadu performed this task correctly. Performance of CMWs from other districts was fair, with the exception of D.G. Khan, where only 2 CMWs out of 14 performed this task correctly.

Table 22: Number of community midwives who correctly performed specific tasks of an abdominal checkup (on a model), by district

\begin{tabular}{lcrrrrrr}
\hline Tasks & Rawalpindi & Jhelum & Khanewal & D.G. Khan & Dadu & Sukkur & Total \\
\hline Size of uterus & 3 & 2 & 10 & 4 & 30 & 4 & 53 \\
\hline Fetal position & 16 & 9 & 13 & 2 & 26 & 4 & 70 \\
\hline Fetal heart rate & 12 & 8 & 9 & 2 & 31 & 4 & 66 \\
\hline $\begin{array}{l}\text { Number of } \\
\text { respondents }\end{array}$ & $\mathbf{1 9}$ & $\mathbf{1 0}$ & $\mathbf{1 7}$ & $\mathbf{1 4}$ & $\mathbf{3 9}$ & $\mathbf{7}$ & $\mathbf{1 0 6}$ \\
\hline
\end{tabular}

Only one-third of the midwives could carry out all three steps correctly (Figure 18). Among the districts, CMWs from Dadu performed the best, followed by Khanewal. 
Figure 18: Percentage of community midwives who correctly carried out all steps of an abdominal examination, by district

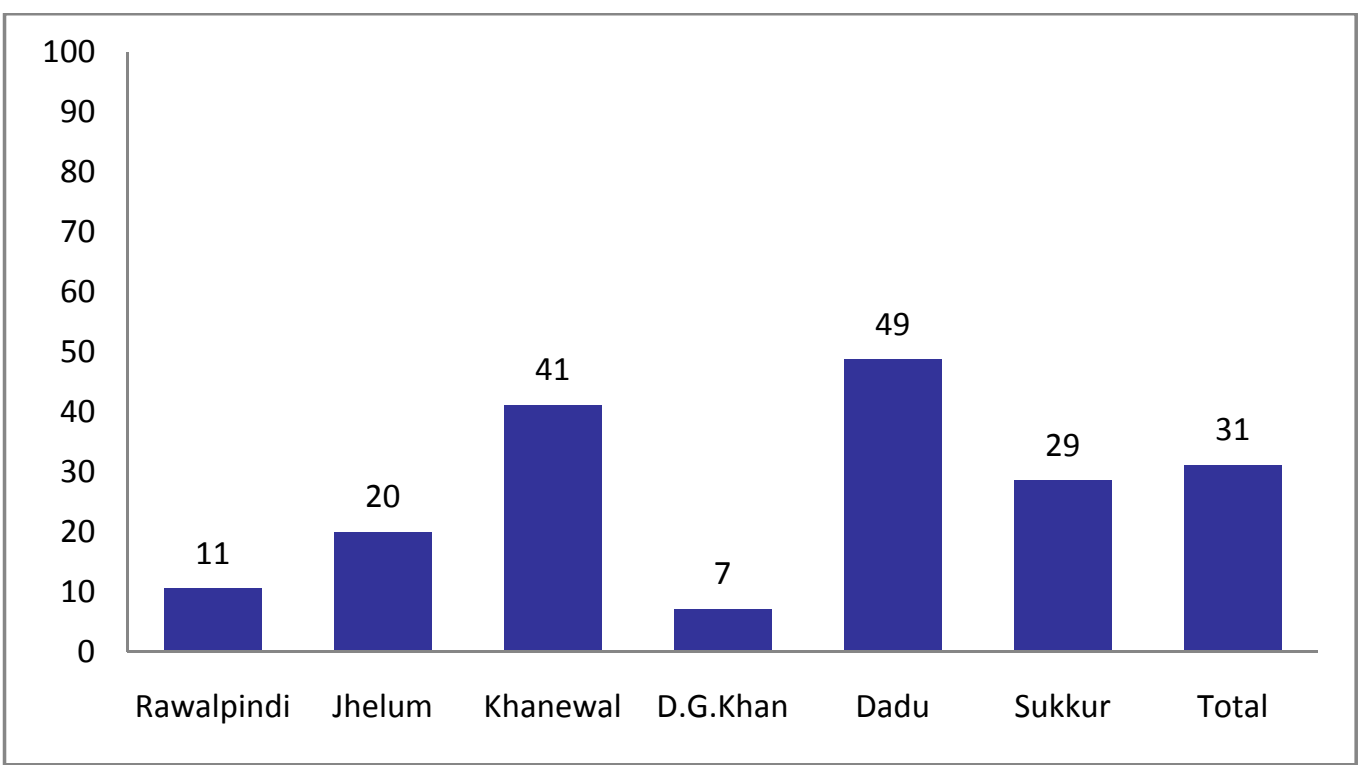

\section{Hand washing}

CMWs were asked to demonstrate proper technique for washing hands: seven steps were assessed, as shown in Table 23. Out of the seven steps, only drying of hands, using soap and washing of hands were completed correctly by a majority of the midwives.

Table 23: Number of community midwives who correctly performed specific steps of hand washing, by district

\begin{tabular}{lrrrrrrr}
\hline Steps & Rawalpindi & Jhelum & Khanewal & D.G. Khan & Dadu & Sukkur & Total \\
\hline $\begin{array}{l}\text { Removing bangles and } \\
\text { rings }\end{array}$ & 5 & 3 & 4 & 7 & 12 & 5 & 36 \\
\hline Cutting of nails & 2 & 1 & 1 & 2 & 9 & 5 & 20 \\
\hline Cleaning of nails & 1 & 1 & 1 & 2 & 10 & 5 & 20 \\
\hline Using soap & 17 & 9 & 3 & 1 & 34 & 6 & 70 \\
\hline Rubbing of hands & 14 & 9 & 1 & 0 & 15 & 5 & 44 \\
\hline Washing of hands & 14 & 8 & 1 & 0 & 24 & 6 & 53 \\
\hline Drying of hands & 17 & $\mathbf{7}$ & 14 & 3 & 33 & 7 & 81 \\
\hline Number of respondents & $\mathbf{1 9}$ & $\mathbf{1 0}$ & $\mathbf{1 7}$ & $\mathbf{1 4}$ & $\mathbf{3 9}$ & $\mathbf{7}$ & $\mathbf{1 0 6}$ \\
\hline
\end{tabular}

The scores for these steps were aggregated for four and more steps and for all seven steps (Figure 19). About a quarter of the midwives could perform four or more steps correctly; a very low proportion of midwives (14 percent) could complete all seven steps 
correctly. Among the districts, the CMWs from Sukkur did well, as 5 out of 7 CMWs washed hands completing all seven steps correctly, followed by Dadu by a wider margin. Not a single midwife from Khanewal or D.G. Khan washed their hands following all seven steps.

Figure 19: Percentage of community midwives who correctly carried out all seven steps of hand washing, by district

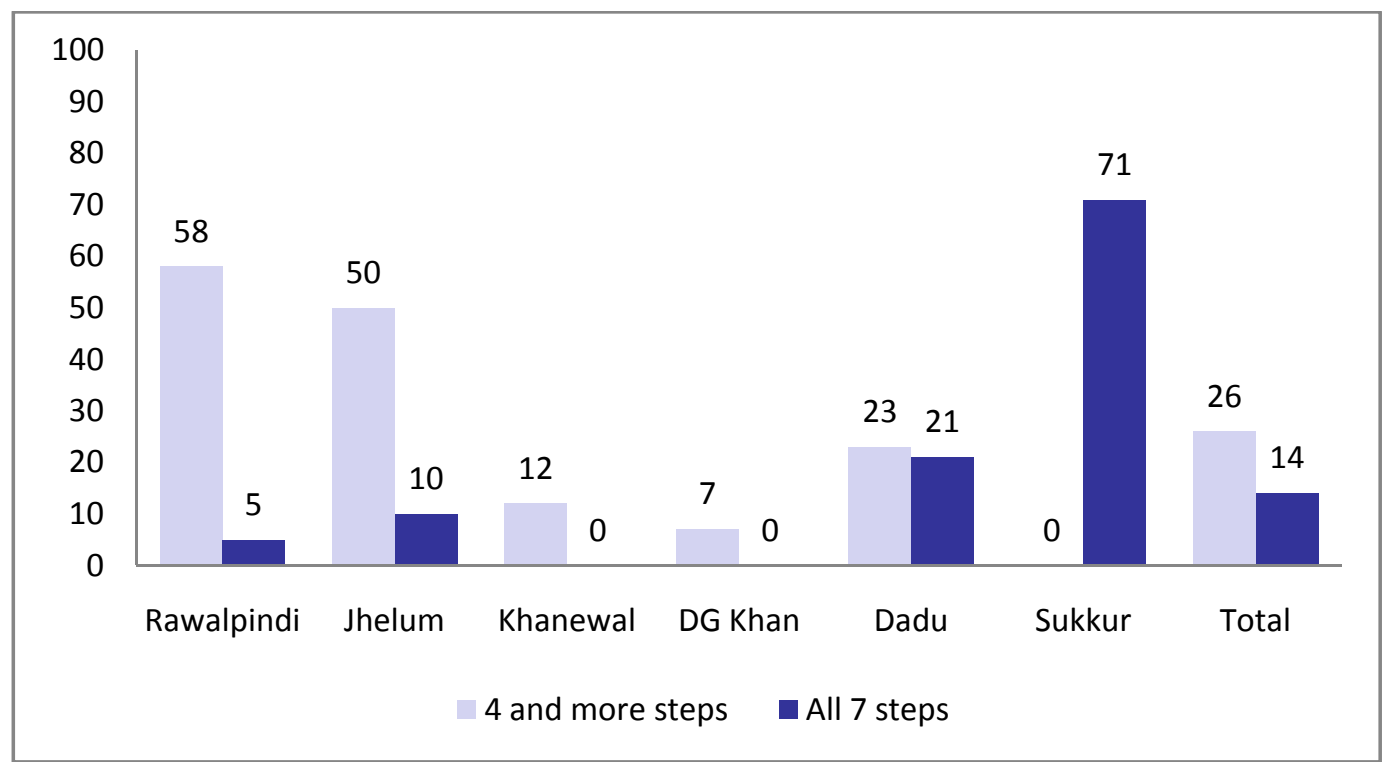

\section{Clean delivery kit}

Properly using a clean delivery kit also helps in maintaining the hygienic conditions at the time of delivery. Midwives were observed for correctly opening and using the clean delivery kit and subsequently putting on the gloves for further use.

Overall, almost half of the CMWs used a clean delivery kit correctly: Those who correctly used the clean delivery kits according to the two skills assessed are shown in Table 24. Across districts, Sukkur and Dadu performed very well for both skills. None of the midwives from D. G. Khan could perform either of the steps correctly, and half of the midwives from the rest of the districts were unable to carry out the task at all or complete both steps correctly. 
Table 24: Number of community midwives who correctly performed specific skills in clean delivery kit use, by district

\begin{tabular}{lrrrrrrr}
\hline Skill & Rawalpindi & Jhelum & Khanewal & D.G. Khan & Dadu & Sukkur & Total \\
\hline Opening the kit & 9 & 6 & 9 & 0 & 33 & 6 & 63 \\
\hline $\begin{array}{l}\text { Using the disposable } \\
\text { gloves }\end{array}$ & 6 & 4 & 9 & 0 & 32 & 6 & 57 \\
\hline Number of respondents & 19 & 10 & 17 & 14 & 39 & 7 & 106 \\
\hline
\end{tabular}

Altogether, less than half of the midwives could perform the two steps correctly (Figure 20). Among districts, the poorest performance was in D.G. Khan where none of the midwives could complete the tasks of using a kit correctly. CMWs from Jhelum and Rawalpindi also did not perform very well.

Figure 20: Percentage of community midwives who correctly carried out both steps in clean delivery kit use, by district

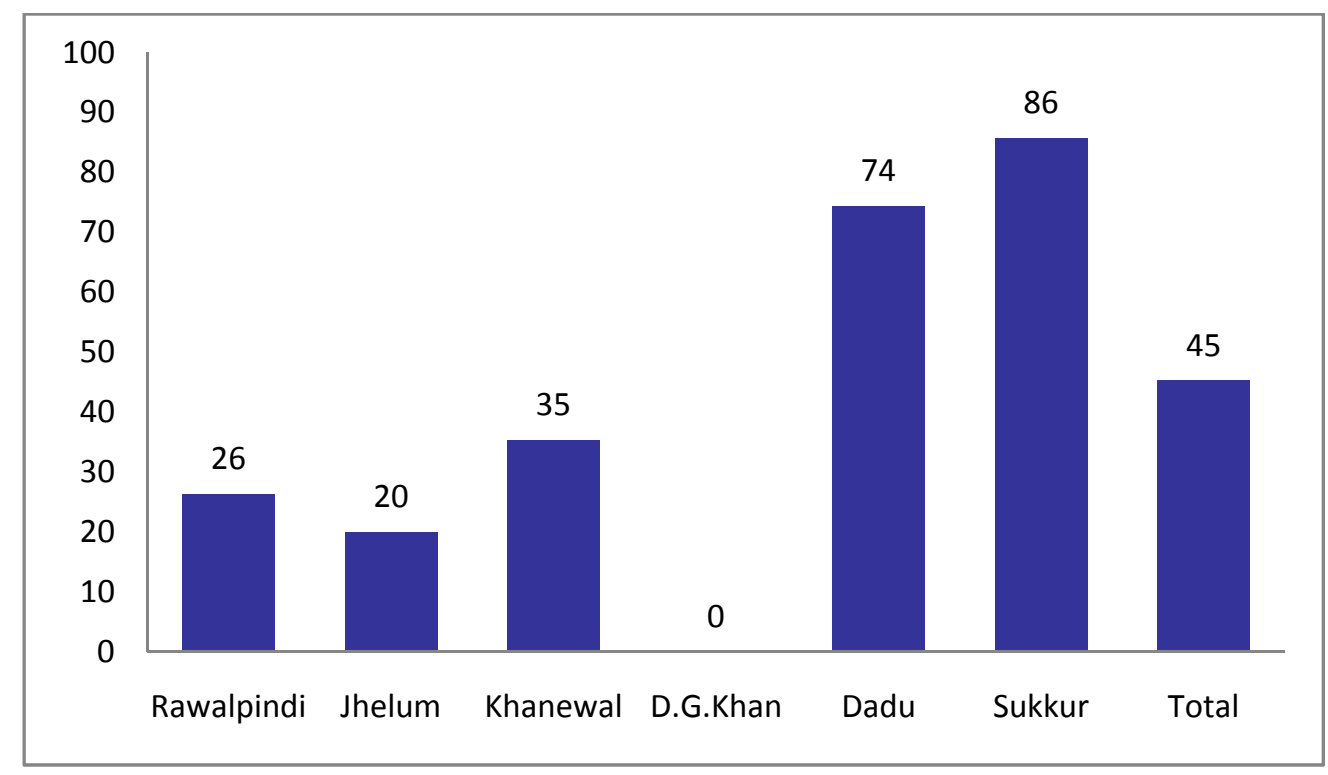

\section{Delivery process}

Various steps are involved at and around the time of delivery of a newborn. Some are related to maintenance of aseptic measures, such as: spreading a clean cloth or a plastic sheet under the woman and cleaning the area; counseling the woman and providing physical support; conducting the delivery of the newborn and handling the newborn. Midwives were assessed using a model for adequately conducting delivery through the following steps: spreading the plastic sheet, cleaning the perineal area, providing perineal 
support, holding the newborn after delivery, wrapping the newborn and cutting the cord. Table 25 shows the results, discussed in the following paragraphs, for all of the steps in the delivery process.

A majority of the midwives performed all steps of delivery correctly except for cleaning the perineal area which is an important step to prevent infection around the time of delivery of a newborn. This step was not often carried out properly. Overall, less than a quarter of the midwives performed the step correctly. Dadu was the district with the highest performance, and only 13 out of 39 CMWs performed the task correctly there.

Perineal support is achieved by placing the palm of the hand around the vulva to provide counter traction while a new born is delivered. This minimizes the risk of uterine prolapse and damage to the cervical neck, which can more easily happen if this support is not provided. Except for D.G. Khan, where only one CMW completed the perineal support task correctly, almost half of the midwives from all districts were able to complete this task correctly.

For better management of a newborn, it is important that after the delivery the newborn be carefully received by an attendant. This should be followed by proper maintenance of the temperature. Midwives from all the districts performed well on this task, except for Khanewal and D.G. Khan, where the performance of the CMWs was very poor.

Table 25: Number of community midwives who correctly performed specific steps of delivery (on a model), by district

\begin{tabular}{|c|c|c|c|c|c|c|c|}
\hline Step & Rawalpindi & Jhelum & Khanewal & D.G. Khan & Dadu & Sukkur & Total \\
\hline $\begin{array}{l}\text { Spreading the plastic } \\
\text { sheet }\end{array}$ & 12 & 8 & 10 & 7 & 27 & 5 & 69 \\
\hline $\begin{array}{l}\text { Cleaning the perineal } \\
\text { area }\end{array}$ & 4 & 1 & 4 & 0 & 13 & 2 & 24 \\
\hline Giving perineal support & 11 & 6 & 8 & 1 & 21 & 3 & 50 \\
\hline $\begin{array}{l}\text { Holding the baby after } \\
\text { delivery }\end{array}$ & 9 & 7 & 5 & 1 & 34 & 7 & 63 \\
\hline Wrapping the baby & 10 & 4 & 4 & 1 & 30 & 6 & 55 \\
\hline Tying the cord & 8 & 9 & 9 & 6 & 29 & 6 & 67 \\
\hline Cutting the cord & 8 & 9 & 10 & 6 & 30 & 7 & 70 \\
\hline $\begin{array}{l}\text { Number of } \\
\text { respondents }\end{array}$ & 19 & 10 & 17 & 14 & 39 & 7 & 106 \\
\hline
\end{tabular}


The score of CMWs for all these steps was cumulated at two levels: for steps four and above and for all seven steps (Figure 21). Performance for the all seven steps was poor, as very few midwives (9 percent) could complete all steps correctly. Even for the CMWs in the best-performing district of Dadu, less than one-fifth were able to accomplish the task correctly using all seven steps. Midwives did better when they were judged on the basis of correctly performing any four or more steps: 10 midwives from Rawalpindi were able to do this, 7 from Jhelum, 32 from Dadu and 6 from Sukkur. However, CMWs in D.G. Khan still performed at a low level, even when judged only by the correct completion of any 4 steps.

Figure 21: Percentage of community midwives who correctly carried out 4 or more steps or all 7 steps of delivery, by district

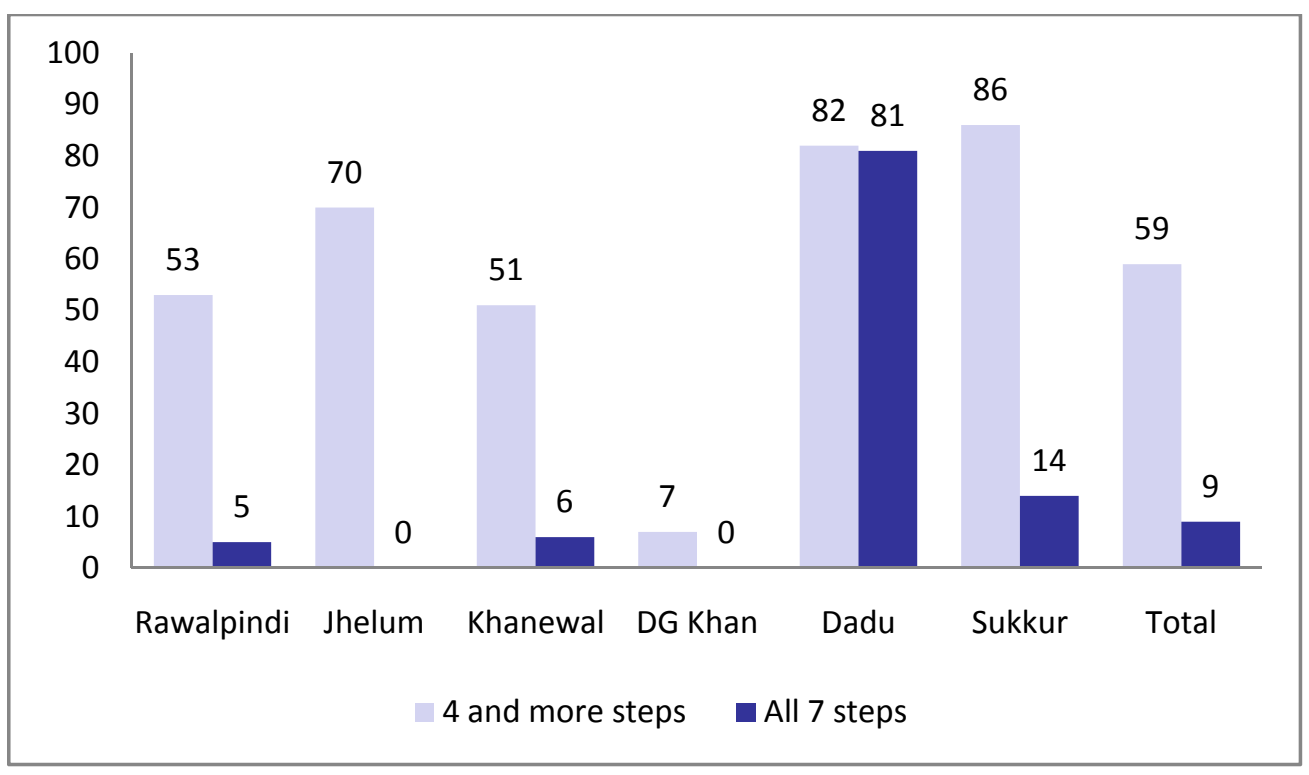

\section{Newborn}

The assessment for testing the skills for caring for a newborn involved: cleaning the mouth, cleaning the eyes, cleaning the face, cleaning the ears, cleaning the nose, cleaning the body and wrapping the newborn in clean cloth.

A clean delivery kit contains four cotton balls and four gauze pieces. Two cotton balls (one for each eye) are meant for cleaning the eyes of the neonate (from inside toward outside). An additional two cotton balls are for cleaning the ears. One gauze piece is used for cleaning the mouth by wrapping it around the little finger and the other is used for 
cleaning the nose. The remaining two gauze pieces are used to hold the cord when tying it.

Table 26 shows the results regarding the steps for caring for a newborn. Overall, except for the task of cleaning the eyes and mouth, the performance for all other steps was poor. Cleaning of the eyes was the step completed correctly by a majority of the CMWs, closely followed by cleaning of the mouth. The performance of the CMWs from D.G. Khan was extremely poor; similarly, the CMWs from Khanewal also performed unsatisfactorily, except for cleaning the mouth and eyes. Sukkur, Jhelum and Dadu were the districts where CMWs performed remarkably well for almost all steps related to newborn care.

Table 26: Number of community midwives who correctly used specific skills in cleaning a newborn, by district

\begin{tabular}{lrrrrrrr}
\hline Skill & Rawalpindi & Jhelum & Khanewal & D.G. Khan & Dadu & Sukkur & Total \\
\hline Clean mouth & 17 & 10 & 8 & 2 & 37 & 3 & 77 \\
\hline Clean eyes & 15 & 9 & 9 & 1 & 39 & 7 & 80 \\
\hline Clean face & 12 & 8 & 3 & 0 & 36 & 7 & 66 \\
\hline Clean ear & 8 & 8 & 1 & 1 & 30 & 7 & 55 \\
\hline Clean nose & 12 & 10 & 2 & 0 & 34 & 4 & 62 \\
\hline Clean body & 12 & 8 & 3 & 1 & 37 & 6 & 67 \\
\hline Wrap in clean cloth & 11 & 6 & 4 & 1 & 33 & 7 & 62 \\
\hline $\begin{array}{l}\text { Number of } \\
\text { respondents }\end{array}$ & $\mathbf{1 9}$ & $\mathbf{1 0}$ & $\mathbf{1 7}$ & $\mathbf{1 4}$ & $\mathbf{3 9}$ & $\mathbf{7}$ & $\mathbf{1 0 6}$ \\
\hline
\end{tabular}

Figure 22 shows the comparison between the cumulative scores for four and more steps and for all steps across districts. Overall, just under one-third of the CMWs (33) could perform any four steps correctly, while 41 midwives were able to accomplish all seven steps correctly. 
Figure 22: Percentage of community midwives who correctly carried out 4 or more steps or all 7 steps of cleaning a newborn, by district

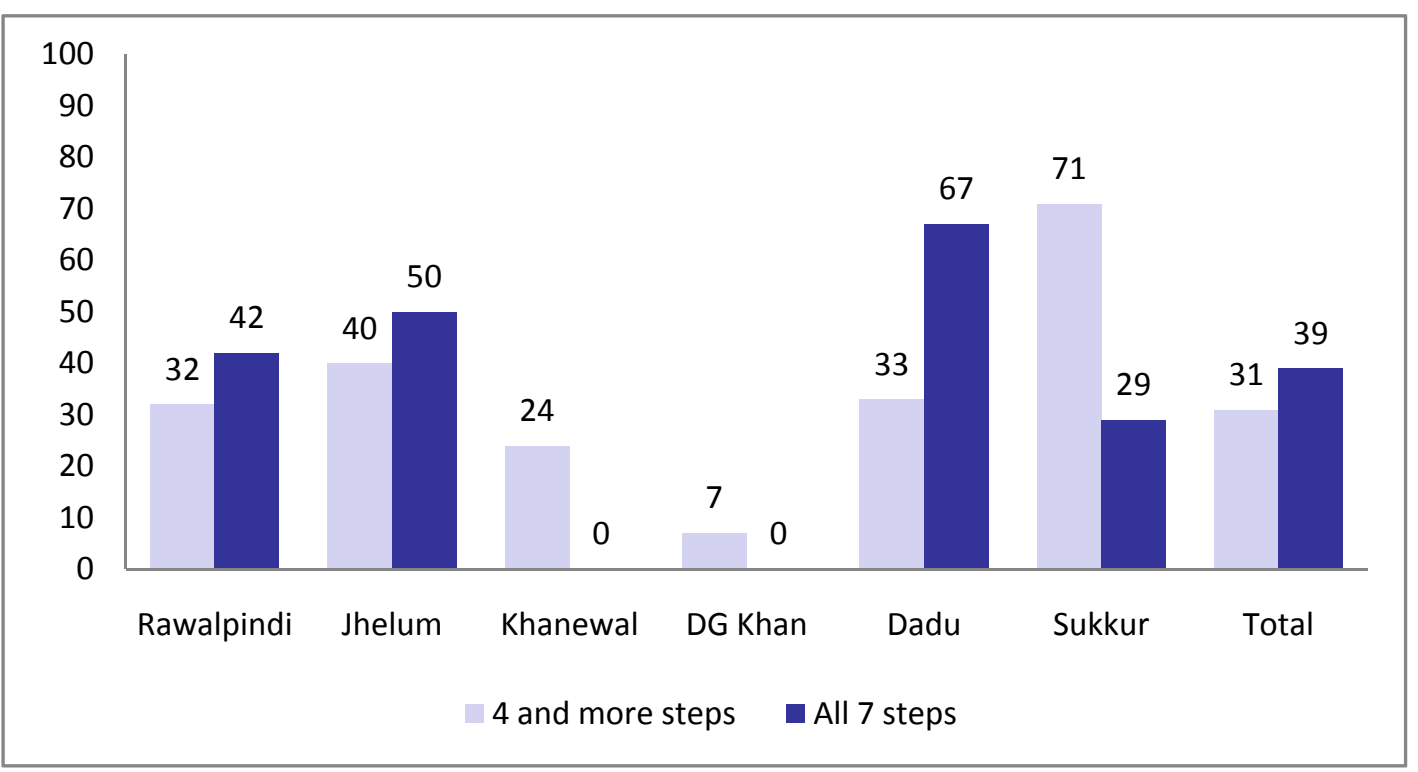

\section{Placenta}

Complete expulsion of the placenta is important to prevent postpartum hemorrhage and puerperal infection, which may result if some portion of the placenta is retained in the uterus. A health care provider can easily check for the expulsion of the placenta manually. The placenta is immersed in water after its removal from the uterus and the outer membranes are examined for any hole or breakage, which is confirmed by manual palpation.

More than half of the CMWs (54) could perform the examination of the placenta immediately after delivery correctly (Figure 23). Midwives from Dadu and Sukkur (36/39 and $6 / 7$, respectively) performed this skill correctly, while no CMWs from Khanewal and D.G. Khan performed the task correctly. 
Figure 23: Percentage of community midwives who correctly carried out all steps in examining the placenta after delivery, by district

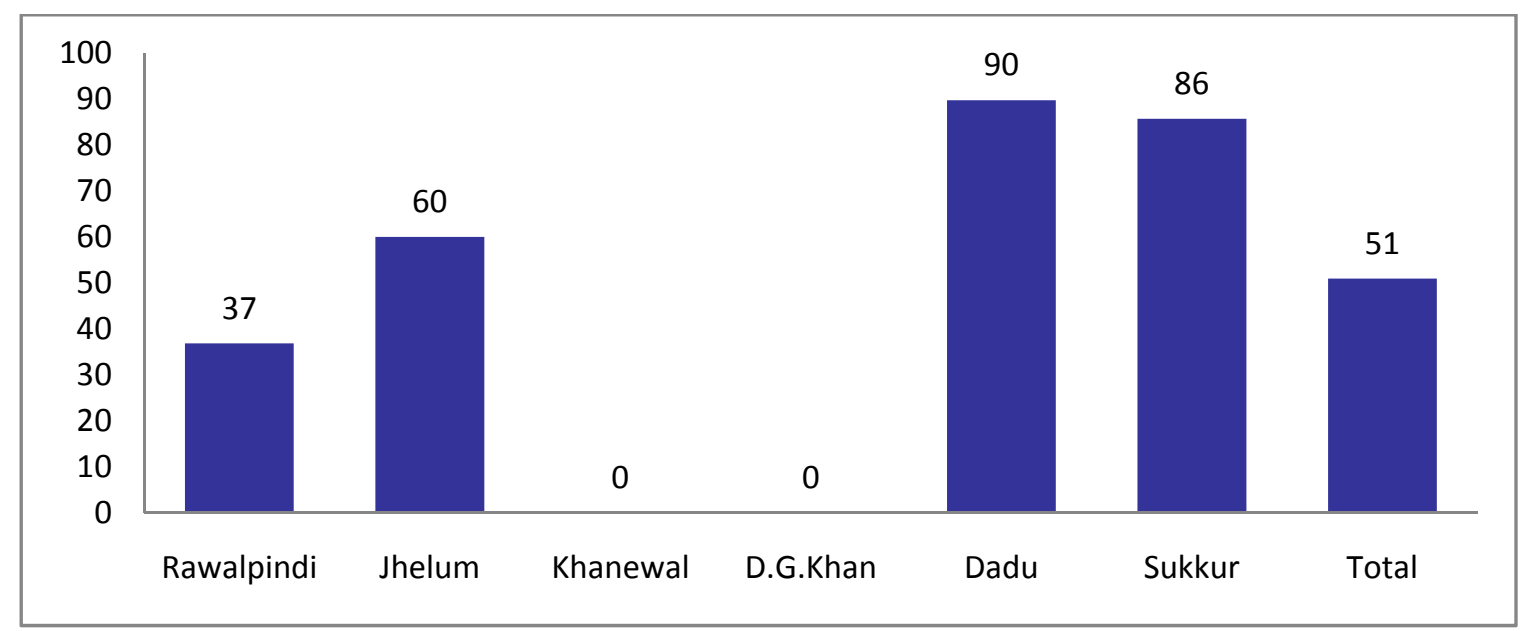




\section{Discussion}

Organized community midwifery on a national scale is a new concept in Pakistan. It is for the first time that a new cadre of health care providers is being introduced. The study explored the training, knowledge, skill assessment and experience of midwives before their placement, some plans/expectations they had about their future. It is expected that this study will contribute to a baseline measurement for the quality and management of community midwifery.

The study revealed that about two-fifths of CMWs (69 out of 174) are not resident in their respective rural communities. CMWs are supposed to reside and establish midwifery homes in their communities. Since many CMWs are not fulfilling this basic requirement, resources are being wasted. This could have been prevented by adhering to a strict recruitment policy.

All of the CMWs fulfilled the requirements for age (at least 18 years of age) and education (minimum of grade 10) for starting their training, as set by the Pakistan Nursing Council (PNC). However, the criterion for training that each student midwife would conduct at least 15 deliveries was not fulfilled by half of the midwives. These midwives admitted the importance of hands-on training in developing skills, as knowledge alone in the absence of practical experience is insufficient.

Though independent midwifery practice has been approved by the government of Pakistan, in reality hospital administrators and medical professionals are not lending their full support to the training of CMWs.

Our results show that married CMWs carried out more deliveries as compared to unmarried. Usually, people avoid having a baby delivered by an unmarried woman. One explanation could be that a married woman, especially who has delivered at least one baby, may be considered to be more mature and well aware of various phases and complications of labor.

To enhance performance, it is suggested that the recruitment policy may consider giving preference to women who have already received prior training in health care such as LHWs. 
A skilled birth attendant should be able to manage a normal delivery, recognize the early signs of major obstetrical complications, perform important life-saving interventions and refer as required (WHO 2004). The midwives knowledge of danger signs of various phases of pregnancy, delivery, and the postpartum period were poor. However, the knowledge possessed by them about the partograph was comparatively better. Similarly, they reflected poor knowledge about management of various complications which arise during these phases. Likewise, their knowledge about neonatal care was also not satisfactory. One of the reasons for performing poorly on knowledge assessment could be that the interviews were conducted about 5-10 months after the final examinations, and many CMWs had not yet been placed in their communities.

The midwives seemed to be aware of their competitors in the community as they expected more cooperation from LHWs as compared to dais. They believed that there would be some element of professional jealousy with the dais. Problems can probably be reduced by establishing a working relationship with the dais and by properly introducing the CMWs into the communities and clearly explaining their roles and responsibilities.

Assessment on skills was carried out by a trained LHV and a model was used for demonstration of various tasks. The skills for assessing anemia were satisfactorily accomplished by CMWs, whereas performance for the rest of the skills related to maternal health was poor. Similarly, performance for correctly completing various skills regarding newborn care was also not very satisfactory. Among the districts, CMWs from D.G. Khan performed extremely poorly, followed by Khanewal. Midwives from the rest of the districts were comparatively better.

Furthermore, these CMWs had limited experience of working in communities during their training. Early exposure to community-based learning throughout the curriculum is of immense value in order to develop the desired competencies, according to an evaluation in South Africa (Mtshali 2005). Provision of in-service training and supervision is another area that needs further consideration. Evidence from an Indonesian study suggests that an intensive in-service training program improved the performance of village midwives in knowledge and five key skills and led to better management of complications as compared to those midwives who had no in-service training (McDermott et.al. 2001).

Performance of CMWs should be monitored through supportive supervision. Being new, this program is lacking in a comprehensive strategy for supervision, which is essential for 
success of any midwifery program. Malaysia made considerable improvement in its MMR by developing a strong supervision and referral system. In Malaysia, maternal and child health committees were established to investigate every maternal and child death and to provide local training sessions for health center staff (Koblinsky et al. 1999).

In order to ensure that all CMWs have essential competencies in both knowledge and skills, a quality assurance system for education and training of CMWs is required. The quality of midwifery training was compromised in Indonesia by focus on the number of trained midwives rather than the quality of their training. As a result, the midwives in Indonesia had insufficient skills to mange complications (Daly and Saadah 1999). A robust accreditation system should be in place to ensure that only those midwifery students qualify who have acquired the required knowledge and skills. 


\section{Recommendations}

1. Opportunities for practical training should be followed meticulously. The training program should be adapted to local contexts in order to ensure sufficient exposure to working within the community during the training period.

2. Selection criteria should be revised especially for age and adherence to the requirement of being resident in the respective rural community.

3. Uniformity of assessment must be ensured through the development of an assessment board. National standards are required for clinical midwifery practice; they should be tailored to the specific rural context.

4. The placement of CMWs must be linked with other $\mathrm{MNCH}$ program activities, such as placement of WMOs, to facilitate referrals and promote health education to create awareness.

5. Supervision is a critical component for ensuring a high quality of services. National standards are required to monitor the practice of CMWs; these standards must go beyond the administrative tasks of reviewing records and ensuring a supportive and capacity-building environment. 


\section{References}

Andersson, T., U. Högberg and S. Bergström. 2000. Community-based prevention of perinatal deaths: lessons from nineteenth-century Sweden. Int. J. Epidemiology. 29: 542-548.

Bhutta, S., S.N. Jafarey and F. Midhet. 2004. Safe Motherhood: A situation analysis and recommendations for evidence-based approaches. Maternal and Child Health in Pakistan, Challenges and Opportunities, ed. Bhutta ZA, 1-17. Oxford University Press, Karachi.

Daly, P. and F. Saadah. 1999. Indonesia: Facing the challenges to reduce maternal mortality. Watching Brief, East Asia and Pacific Region. Issue3.

Department of Health. 1997. Training 2000. Instruction manual for medical officers, women medical officers and lady health visitors. Lahore.

Federal Bureau of Statistics. 2005. Monthly Bulletin of Statistics. Statistics Division. Islamabad.

Hatt, L., C. Stanton, K. Makowiecka, A. Adisasmita, E. Achadi and C. Ronsmans. 2007. Did the strategy of skilled attendance at birth reach the poor in Indonesia? Bull WHO 85(10): 774-783.

Hogberg, U. 2004. The decline in maternal mortality in Sweden: The role of community midwifery. Am J Pub Health. 94(8): 1312 - 1320.

Koblinsky, M.A., O. Campbell and J. Heichelheim. 1999. Organizing delivery care: what works for safe motherhood? Bull WHO 77(5): 399-406.

McDermott, J., D. Beck, S.T. Buffington, J. Annas, G. Supratikto, D. Prenggono, F.M. Sri Ekonomi, E. Achadi, Achadi E. 2001. Two models of in-service training to improve midwifery skills: how well do they work? Journal of Midwifery and Women's Health; 46(4):217-225.

Ministry of Health (MOH). 2006. National maternal newborn and child health (MNCH) program, PC-1. Islamabad. 
Mordechai Hallak. 1999. Hypertension in pregnancy. High risk pregnancy: management option, Second edition.W.B.Saunders P-639-663

Mtshali, N.G. 2005. Conceptualisation of community-based basic nursing education in South Africa: a grounded theory analysis. Curationis. May 28 (2); 5-12

NIPS/USAID. 2007. Pakistan Demographic and Health Survey 2006-07. Measure DHS, Macro International Inc. Calverton, Maryland, USA.

Pakistan Nursing Council. 2005. Midwifery curriculum, Islamabad, Pakistan.

UNFPA-ICM. 2006. Investing in Midwives and others with Midwifery Skills to Save the Lives of Mothers and Newborns and Improve their Health. A joint initiative to support the call for a Decade of Action for Human Resources for Health made at World Health Assembly, 2006.

Wajid, A., Mir, A.M., Rashid, Z., 2010. Assessing the acceptability of a new cadre of community midwives for pregnancy and delivery related care in rural Pakistan: Findings from a qualitative study. Population Council, Pakistan

World Health Organization. 2004. Making pregnancy safer: The critical role of the skilled attendant, a joint statement by WHO, ICM, and FIGO, 2004. World Health Organization, Geneva.

World Health Organization. 2005. Make every mother and child count. The World Health Report 2005. 1211 Geneva 227, Switzerland. http://www.who.int/whr/2005/en/ (accessed June 20, 2008). 
Appendix 1: Field Researchers

\begin{tabular}{l|l|l}
\hline Name & Position & District \\
\hline Nighat Yasmeen & Interviewer & Rawalpindi/Jhelum \\
\hline Nazma Naz & Interviewer & Rawalpindi/Jhelum \\
\hline Waqar Hussain & Logistic Supervisor & Rawalpindi/Jhelum \\
\hline Shaista Parveen & Interviewer & D.G. Khan/Khanewal \\
\hline Sehrish Qayyum & Interviewer & D.G. Khan/Khanewal \\
\hline Abdul Qadir & Logistic Supervisor & D.G. Khan/Khanewal \\
\hline Wahida Feroz & Interviewer & Dadu/Sukhur \\
\hline Aftab Mangi & Logistic Supervisor & Dadu/Sukhur \\
\hline
\end{tabular}

58 


\section{JSA}

JSI Research \& Training Institute, Inc.

CA\#391 A-00-05-01037 is funded by the United States Agency for International Development and implemented by JSI Research \& Training Institute, Inc.

In conjunction with Aga Khan University, Contech International, Johns Hopkins University / CCP, The Population Council, Save the Children USA 